\title{
A Triarylated 1,2,3-Triazol-5-ylidene Ligand with a Redox-Active Ferrocenyl Substituent for Rhodium(I)-Catalyzed Hydroformylation of 1-Octene
}

\author{
Danielle Aucamp, ${ }^{[a]}$ Tim Witteler, ${ }^{[b]}$ Fabian Dielmann, ${ }^{[b]}$ Shepherd Siangwata, ${ }^{[c]}$ \\ David C. Liles, ${ }^{[a]}$ Gregory S. Smith, ${ }^{[c]}$ and Daniela I. Bezuidenhout*[a,d]
}

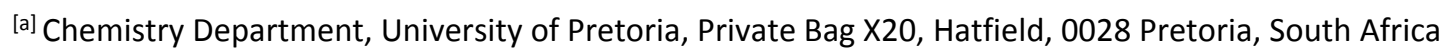 \\ [b] Institut für Anorganische und Analytische Chemie, Westfälische Wilhelms-Universität Münster, \\ Corrensstrasse 30, Münster 48149, Germany \\ ${ }^{[c]}$ Department of Chemistry, University of Cape Town, 7701 Rondebosch, South Africa \\ [d] Molecular Sciences Institute, School of Chemistry, University of the Witwatersrand, Johannesburg 2050, \\ South Africa \\ *E-mail: daniela.bezuidenhout@wits.ac.za
}

\begin{abstract}
A series of rhodium(I)-1,2,3-triazol-5-ylidene (trz) complexes are described, containing either a novel triarylated trz ligand $\mathbf{A}^{\prime}$ (N1, N3-arylated, C4-ferrocenyl) \{complexes $\mathbf{1}$, $\left.\left[\mathrm{Rh}\left(\mathbf{A}^{\prime}\right) \mathrm{Cl}(\operatorname{cod})\right] ; \mathbf{4},\left[\mathrm{Rh}\left(\mathbf{A}^{\prime}\right) \mathrm{Cl}(\mathrm{CO}) 2\right]\right\}$, or N3-alkylated triazolylidenes with a C4-ferrocenyl $\{\mathbf{2}$, $\left.\left[\mathrm{Rh}\left(\mathbf{B}^{\prime}\right) \mathrm{Cl}(\mathrm{cod})\right] ; \mathbf{5},\left[\mathrm{Rh}\left(\mathbf{B}^{\prime}\right) \mathrm{Cl}(\mathrm{CO}) 2\right]\right\}$ or $\mathbf{C 4}$-phenyl substituent $\left\{\mathbf{3},\left[\mathrm{Rh}\left(\mathbf{C}^{\prime}\right) \mathrm{Cl}(\operatorname{cod})\right] ; \mathbf{6}\right.$, $\left.\left[\mathrm{Rh}\left(\mathbf{C}^{\prime}\right) \mathrm{Cl}(\mathrm{CO}) 2\right]\right\}$. The free mesoionic carbene (MIC) $\mathbf{A}^{\prime}$ is structurally characterized and its electronic properties evaluated by employing the complex $\left[\mathrm{Pd}(\mathrm{Br}) 2(\mathrm{iPr} 2-\right.$ bimy $\left.)\left(\mathbf{A}^{\prime}\right)\right](\mathbf{7})$ in an NMR spectroscopic analysis method. The redox activity of $A^{\prime}$ is exploited, and the chemically oxidized precursor Aox and complex 4ox are isolated. The mesoionic carbene complexes 13, as well as in situ oxidized 1ox, are used as homogeneous catalysts for the hydroformylation of 1-octene for the first time, and the influence of chemical oxidation of the catalyst on the activity and chemo- and regioselectivity of the catalyst precursor $\mathbf{1}$ is evaluated.
\end{abstract}

\section{Introduction}

The use of redox-switchable catalysts has become an increasingly popular strategy to improve both the activity and selectivity of selected homogeneous catalytic processes[1] Particularly, the incorporation of a redox-active functionality, such as ferrocene in close proximity to the active catalytic metal site in heterodimetallic complexes, has been shown 
to influence the ligand-based reactivity of the metal complexes to offer an additional handle on catalyst-ligand design and fine-tuning.[2]

For the hydroformylation of olefins, numerous examples of rhodium(I)-based catalysts with a ferrocenyl ligand substituent have been reported;[3] however, the effect of the redox activity of these ferrocenyl substituents on the performance of the catalysts remains unexplored. Similarly, we have recently reported the syntheses of a range of rhodium(I)ferrocenyl-Fischer-carbene catalyst precursors for the hydroformylation of 1-octene. [4] In an effort to maintain sufficient electron density on the rhodium(I) centre for maximum conversion of the terminal olefins, whereby the linear aldehydes are the preferred hydroformylation product for most applications, an increase in the $n$ /iso ratio of the product aldehydes were targeted by modifying the electrophilic $\pi$-acceptor carbene ligands with an electron-donating ferrocenyl substituent.[5] The success of these results prompted us to prepare di- and triarylated 1,2,3-triazol-5-ylidene (trz) rhodium(I) complexes containing a ferrocenyl substituent on the $\mathrm{C} 4$ position of the triazol ring.

A subclass of the so-called abnormal $\mathrm{N}$-heterocyclic carbenes ( $a \mathrm{NHCs}$ ) or mesoionic carbenes (MICs), 1,2,3-triazol-5-ylidenes, have been shown to be stronger donors than $\mathrm{N}$ heterocyclic carbenes (NHCs), but weaker donors than imidazol-4-ylidene-based MICs.[6] This modular feature of these ligands, coupled with the redox activity of the ferrocenyl moiety, paves the way to tailoring catalyst performance (chemo- and regioselectivity as well as catalyst activity). The electrochemical behaviour and the effect of the chemical oxidation of the ferrocenyl moiety to an electron-withdrawing ferrocenium substituent on the catalyst precursor performance are also reported herein.

\section{Results and Discussion}

\section{Synthesis and Characterization of Catalyst Precursors}

The new triarylated ligand precursor 4-ferrocenyl-1,3-diaryl-1H-1,2,3-triazolium salt A[7] was prepared by cycloaddition of ethynylferrocene and 1,3-bis(2,6-diisopropylphenyl)triaz1-ene (2,6-diisopropylphenyl = Dipp), according to an adapted literature procedure. [8] The diarylated, N3-alkylated salts, 4-Ar-1-Dipp-3-ethyl-1H-1,2,3-triazolium precursors B (Ar = Fc) and $\mathbf{C}(\mathrm{Ar}=\mathrm{Ph})[7]$ were prepared according to a modified literature procedure[3e], [6b], [9] from their corresponding known triazoles.[10] The rhodium complex 1 was prepared in a stepwise manner by generating the free 1,2,3-triazol-5-ylidene ( $\mathbf{A}^{\prime}$; vide infra),[6b] obtained after deprotonation of the triazolium salt precursor $\mathbf{A}$ with potassium hexamethyldisilazide (KHMDS). Access to the free MIC is possible due to the enhanced kinetic stability afforded by the N3-aryl substituent, compared with the N3-alkylated triazolylidenes.[8] Addition of the free carbene to the metal precursor $[\mathrm{Rh}(\operatorname{cod}) \mathrm{Cl}] 2$ ( $\mathrm{cod}=1,5$-cyclooctadiene; Scheme 1a), afforded $\mathbf{1}$ in $\mathbf{8 3} \%$ yield. Complexes $\mathbf{2}$ and $\mathbf{3}$ were prepared in a one-pot synthetic route by in situ deprotonation of ligand precursors $\mathbf{B}$ and $\mathbf{C}$, and coordination of the triazolylidenes $\mathbf{B}^{\prime}$ and $\mathbf{C}^{\prime}$, respectively, to $[R h(\mathrm{cod})(\mathrm{Cl})] 2$ (Scheme $\left.1 \mathrm{~b}\right)$. In the $1 \mathrm{H}$ NMR spectra of 1 , the proximity of the ferrocenyl substituent to the Rhl centre is demonstrated by the downfield shift $(\delta=6.98 \mathrm{ppm})$ of the signal of the $\alpha$-protons of the substituted cyclopentadienyl ring, compared with the chemical shift of the signal of the $\alpha$-protons in the triazolium salt $\mathbf{A}(\delta=$ 4.56 ppm; see Supporting Information). To a lesser extent, this steric crowding is also 
observed in $\mathbf{2}$ ( $\delta=5.85$ for the $\alpha-\mathrm{H}$ of Fe-Cp' compared with $\delta=4.91$ for B). The donor properties of the MICs are reflected in the low-field shifts of the carbene resonances compared with those of Rh-NHC complexes,[11] with the carbene carbon doublets observed at $\delta=171.9$ (1), 172.3 (2) and $173.2 \mathrm{ppm}(3)$ having Rh-C coupling constants of $J=$ $46.6,47.1$ and $47.3 \mathrm{~Hz}$, respectively. The known electron-donating characteristics of the ferrocenyl substituent[12] are reflected in an upfield shift of ferrocenyl-substituted triazolylidene complexes $(\mathbf{1}, \mathbf{2})$, compared with the phenyl-substituted 3.[8] However, surprisingly, these triazolylidene-carbene resonances occur on the lower field end of the range of carbene chemical shifts reported for other neutral RhI-trz complexes $(\delta=161-172$ ppm).[6a], [13] 
(a)

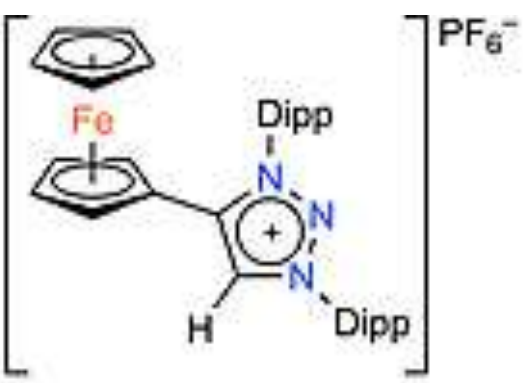

A

\section{(i) $\mathrm{KN}\left[\mathrm{Si}\left(\mathrm{Me}_{3}\right)_{2}\right]$ \\ THF \\ $-78^{\circ} \mathrm{C}$ \\ (ii) $[\mathrm{Rh}(\operatorname{cod}) \mathrm{Cl}]_{2}$}

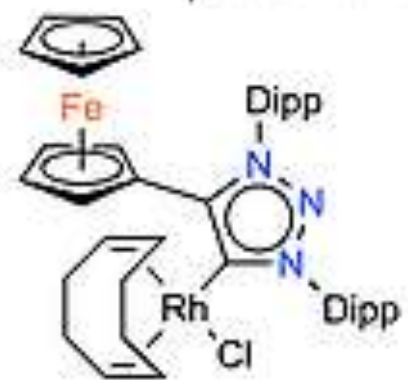

$1(83 \%)$<smiles></smiles>

$4(87 \%)$

Dipp $=2$,6-diisopropylphenyl $\operatorname{cod}=1,5$-cyclooctadiene (b)<smiles></smiles>

$\mathrm{B}: \mathrm{Ar}=\mathrm{Fc}$

$\mathrm{C} ; \mathrm{Ar}=\mathrm{Ph}$

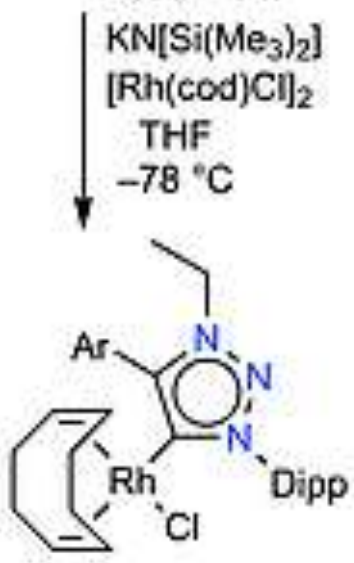

2; $\mathrm{Ar}=\mathrm{Fc}(59 \%)$

$3: \mathrm{Ar}=\mathrm{Ph}(30 \%)$

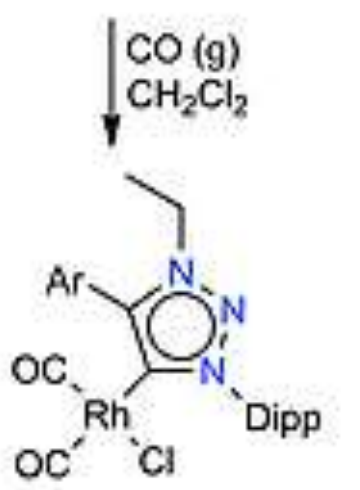

5: $\mathrm{Ar}=\mathrm{FC}(33 \%)$

6: $\mathrm{Ar}=\mathrm{Ph}(22 \%)$

Scheme $\mathbf{1}$. Synthesis of tri- $(\mathbf{1}, \mathbf{4})$ and diarylated $(\mathbf{2}, \mathbf{3}, \mathbf{5}$ and $\mathbf{6})$ triazolylidene-Rhl complexes.

The dicarbonyl complexes 4-6 were prepared by treatment of the corresponding cod complexes 1-3 in dichloromethane with excess carbon monoxide (Scheme 1). Single-crystal $\mathrm{X}$-ray diffraction studies of the square-planar complexes 1, $\mathbf{2}$ and $\mathbf{4}$ (Figure 1), showed that the Rh-Ccarbene bond lengths [2.059(2) for 1, 2.053(3) for 2, 2.079(4) A for 4] are in accordance with those of previously reported structures.[13] The effect of the changes in the electronic structure around the metal atom, with the more $\pi$-accepting carbonyl ligands, compared with the cod ligands, result in a lengthening of the Rh-Ccarbene bond for 4, compared with those of $\mathbf{1}$ and $\mathbf{2}$. For these complexes, the carbene carbon doublets in the 
13C NMR spectra were shifted upfield [ $\delta=165.8(4), 165.2(5), 166.2 \mathrm{ppm}(6)]$, with the CO ligands resonating in the range $\delta=183.4-186.1 \mathrm{ppm}$. However, no clear distinction on the effects of N3- or C4-substitution can be made from these results. Inspection of the Tolman electronic parameter (TEP)[14] of the dicarbonyl-trz-RhI complexes to investigate both the effect of the donating C4-ferrocenyl and N3-substituent [aryl ( $\left.\mathbf{A}^{\prime}\right)$ vs. alkyl $\left(\mathbf{B}^{\prime}, \mathbf{C}^{\prime}\right)$ ], did not prove a sufficient probe for the evaluation of subtle ligand-substituent effects (i.e., N1, N3 and C4 substituents),[8] as TEPs calculated according to the linear regression model reported by Glorius et al. from the measured FT-IR spectra of 4-6, in all three cases, yielded a value of $2047 \mathrm{~cm}-1,[15]$ similar to those of other trz-Rh/Ir complexes.[6] To overcome the limitations of the TEP measurements, it was therefore decided to employ the 13C NMR spectroscopic method reported by Huynh et al., whereby a range of trans-[PdBr2(iPr2bimy)(trz)] (iPr2-bimy = 1,3-diisopropylbenzimidazolin-2-ylidene) complexes have been previously evaluated using the carbene carbon resonance of the iPr2-bimy ligand as a sensitive probe to determine the donor strength of the trz ligands.[16] For this reason, the novel free trz ligand $\mathbf{A}^{\prime}$ was isolated, after deprotonation of $\mathbf{A}$ by $\mathrm{KO}$ tBu, and treated with the precursor $[\mathrm{Pd}(\mathrm{Br}) 2(i \mathrm{Pr} 2-$ bimy $)] 2$ to yield complex 7, $\left[\mathrm{Pd}(\mathrm{Br}) 2(i \mathrm{Pr} 2-\right.$ bimy $\left.)\left(\mathbf{A}^{\prime}\right)\right]$ (Scheme 2). Solid-state structures of both the free MIC $A^{\prime}$ (Figure 2) and complex 7 (Figure 3 ) could be obtained after isolation of suitable single crystals for $\mathrm{X}$-ray diffraction studies. The carbene carbon chemical shift of $\mathbf{A}^{\prime}$ is $\delta=201.7 \mathrm{ppm}$ in C6D6, comparable with triazolylidenes being either alkylated at N3 (ranging between $\delta=198$ and $202 \mathrm{ppm}$ ) or arylated at the N3 position $(\delta=200-206 \mathrm{ppm})$. However, inspection of the carbene shifts of both coordinated $\mathbf{A}^{\prime}$ and the iPr2-bimy ligand in $\mathbf{7}$ provides information on the substituent effects of $\mathbf{A}^{\prime}$ : in $\mathrm{CDCl}$, the MIC C-atom chemical shift of $A^{\prime}$ is observed at $\delta=162.2 \mathrm{ppm}$, more low-field than any of the previously evaluated N3-alkylated trz ligands (ranging from $\delta=157.9$ to $160.6 \mathrm{ppm}$ ). In addition, the $\operatorname{Pr} 2$-bimy NHC C-atom resonance is observed at $\delta=179.5 \mathrm{ppm}$, more highfield than any previously reported for trz complexes $(\delta=180.3-181.2 \mathrm{ppm}),[16]$ thus confirming the weaker donor ability of N3-arylated, C4-ferrocenyl-substituted $\mathbf{A}^{\prime}$, with no significant electron donation from the proximal Fc group towards the trz ring. 


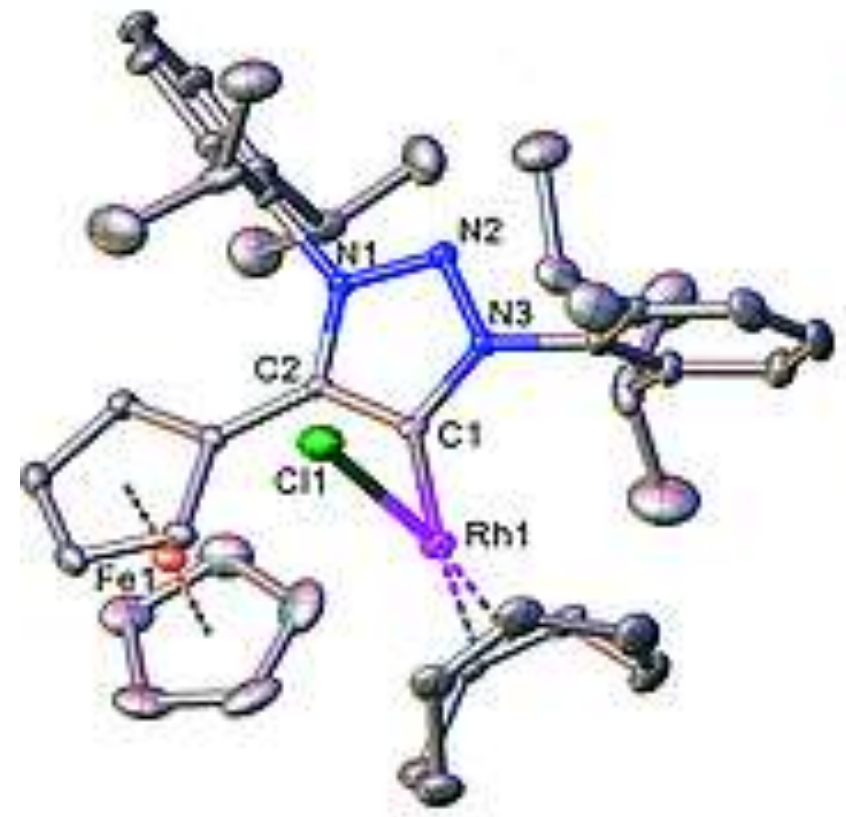

1

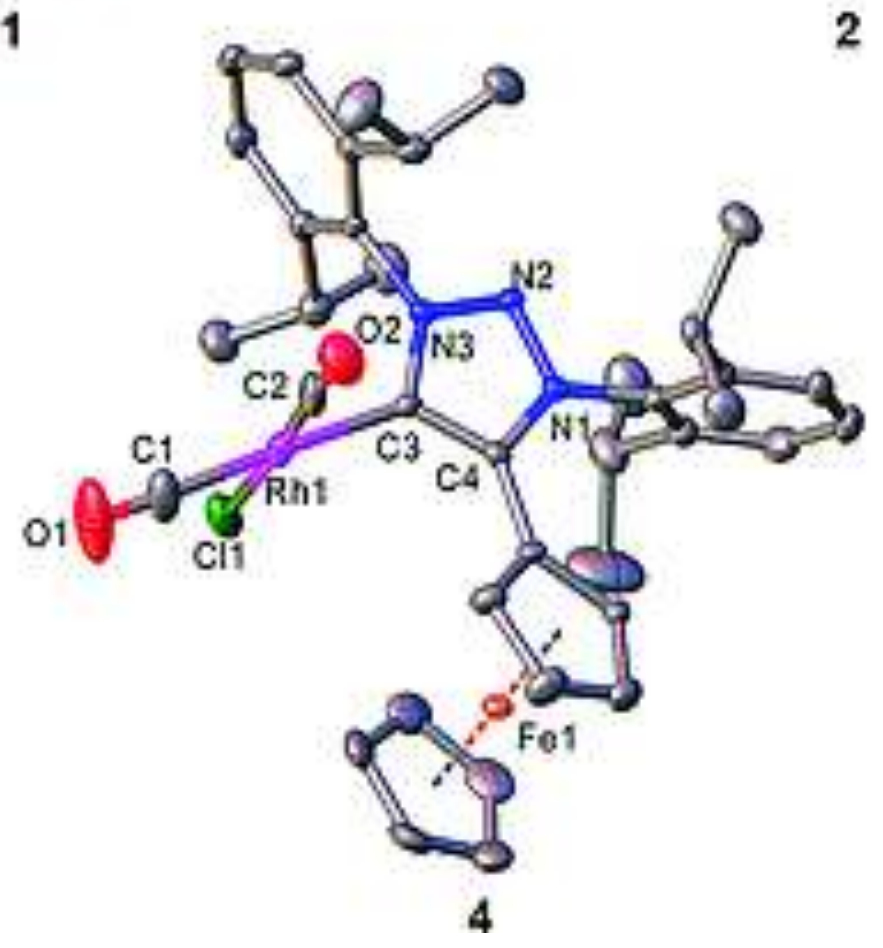

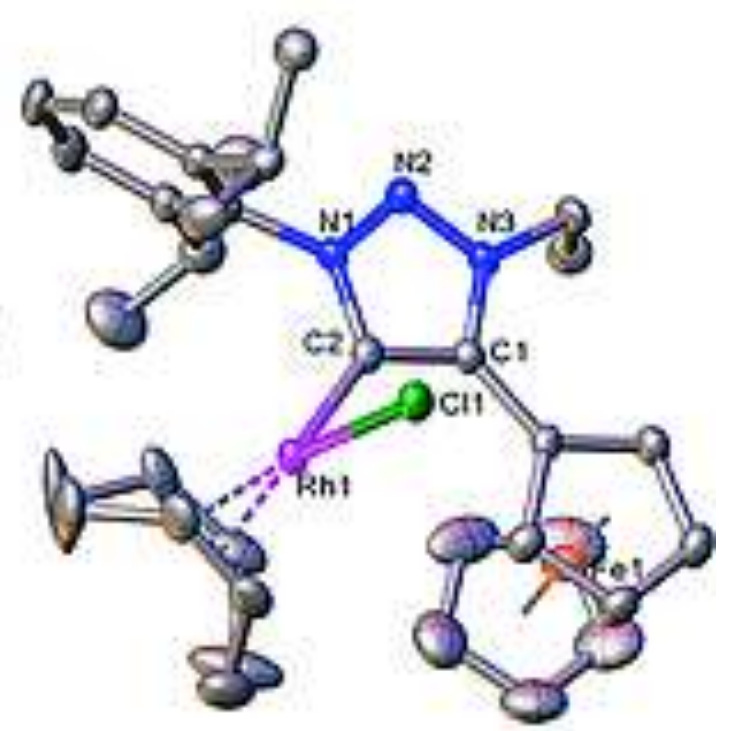

2

Figure 1. Molecular structures of triazolium-rhodium(I) complexes 1, 2 and $\mathbf{4}$, showing $50 \%$ probability ellipsoids and partial atom-numbering scheme. Hydrogen atoms were omitted for clarity. Selected bond lengths $[\AA ̊]$ and angles [ $\left.{ }^{\circ}\right]$ for 1: C1-Rh1 2.059(2), N1-N2 1.328(3), N1-C2 1.370(3), N2-N3 1.335(2), N3-C1 1.375(3), C1-C2 1.403(3), N3-C1-C2 101.40(17), C1-Rh1-Cl1 87.22(6). For 2 : C1-Rh1 2.053(3), N1-N2 1.339(3), N2-N3 1.317(3), N3-C1 1.369(3), C1-C2 1.406(4), N1-C2 1.374(4), N1-C2-C1 101.90(2), C2-Rh1-Cl1 87.33(8); for 4: Rh1-C3 2.079(4), Rh1-C1 1.896(5), Rh1-C2 1.868(15), N1-N2 1.335(4), N1-C4 1.376(5), N2-N3 1.334(4), N3-C3 1.375(5), C3-C4 1.393(5), N3C3-C4 102.50(3), C3-Rh1-Cl1 90.80(12). 


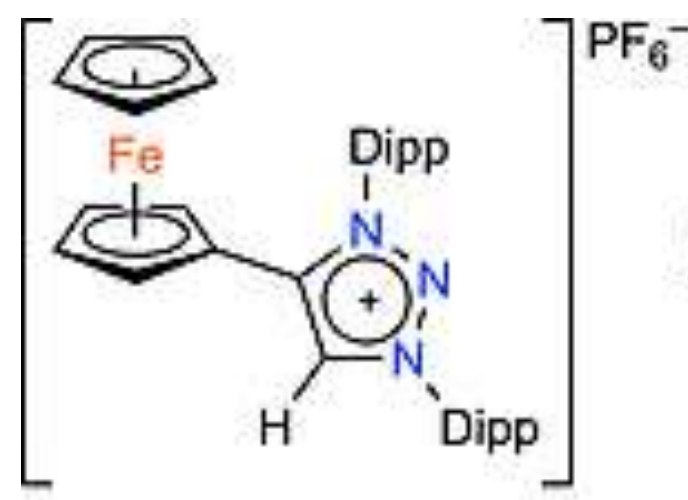

A

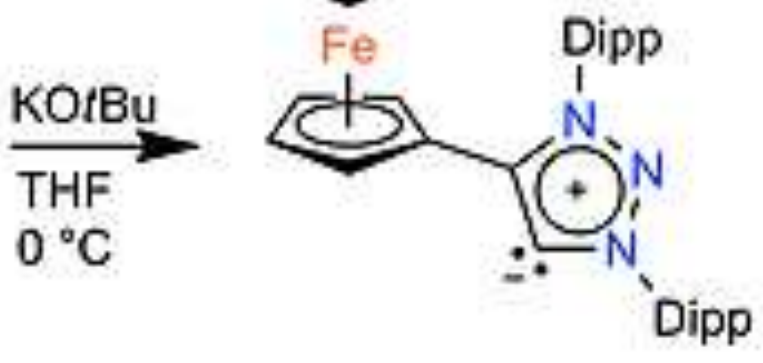

$A^{*}(67 \%)$

Dipp $=2$,6-diisopropylphenyl

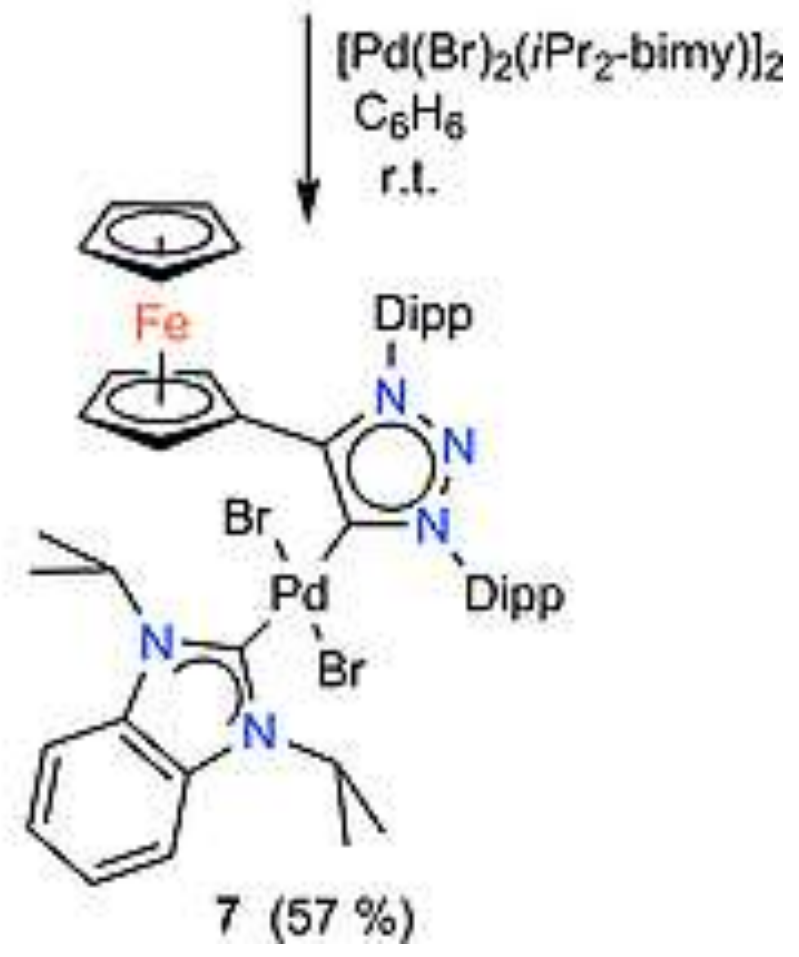

Scheme 2. Synthesis of free carbene $\mathbf{A}^{\prime}$ and PdII complex $\mathbf{7}$. 

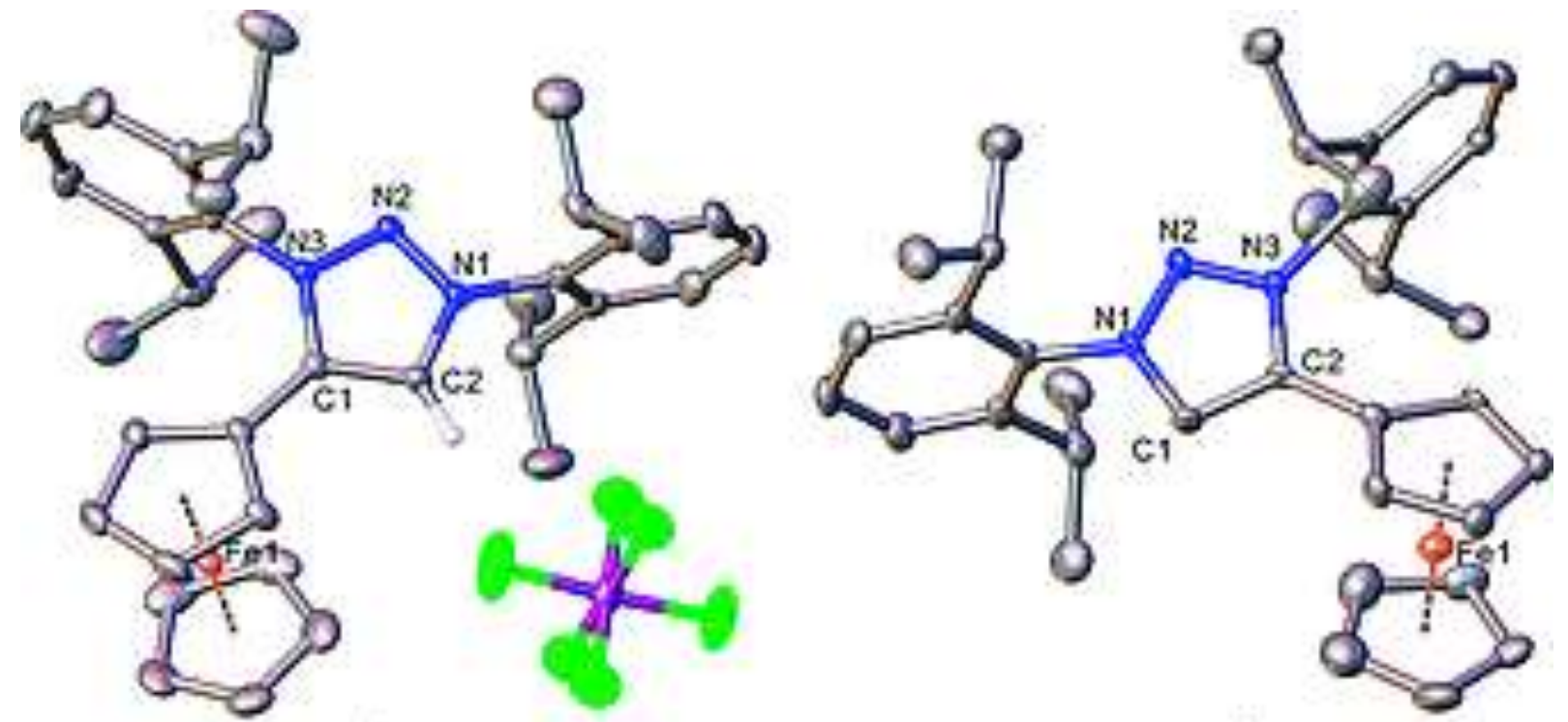

A

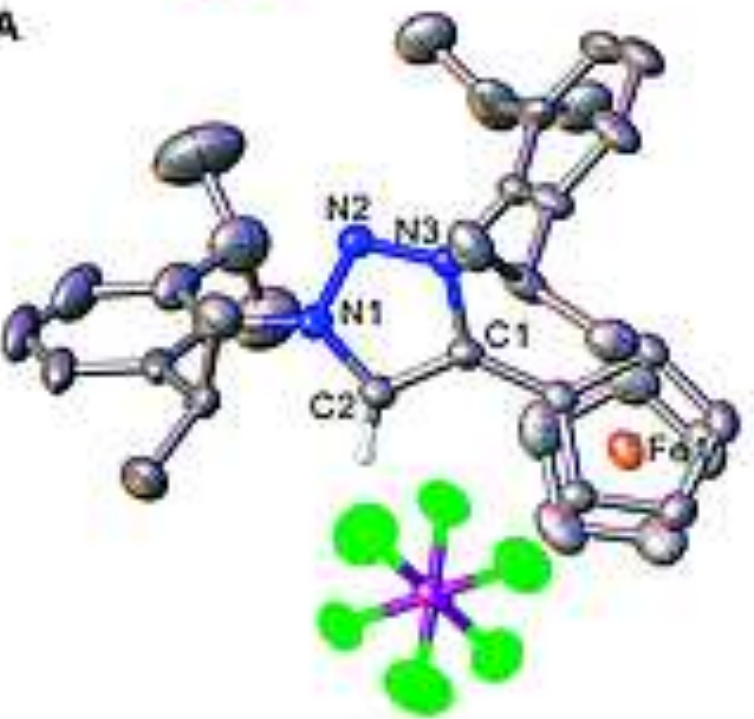

A

$A_{\text {ox }}$

Figure 2. Molecular structures of the cationic triazolium salt $\mathbf{A}$, the free carbene $\mathbf{A}^{\prime}$ and the dicationic ferrocenium triazolium salt Aox showing $50 \%$ probability ellipsoids and partial atom-numbering scheme. Hydrogen atoms (except for the trz-H) are omitted for clarity. Selected bond lengths $[\AA]$ and angles $\left[{ }^{\circ}\right]$ for $\mathbf{A}$ : N1-N2 1.328(3), N1-C2 1.348(3), N2-N3 1.338(3), N3-C1 1.369(3), C1-C2 1.383(3), N1-C2-C1 106.00(19); for $A^{\prime}$ : N1-N2 1.344(4), N1-C1 1.387(5), N2-N3 1.349(4), N3-C2 1.393(5), C1-C2 1.393(5), N1-C1-C2 99.6(3); for Aox: N1-N2 1.320(3), N1-C2 1.348(3), N2-N3 1.321(3), N3-C1 1.370(3), C1-C2 1.364(3), N1-C2-C1 105.70(2). 

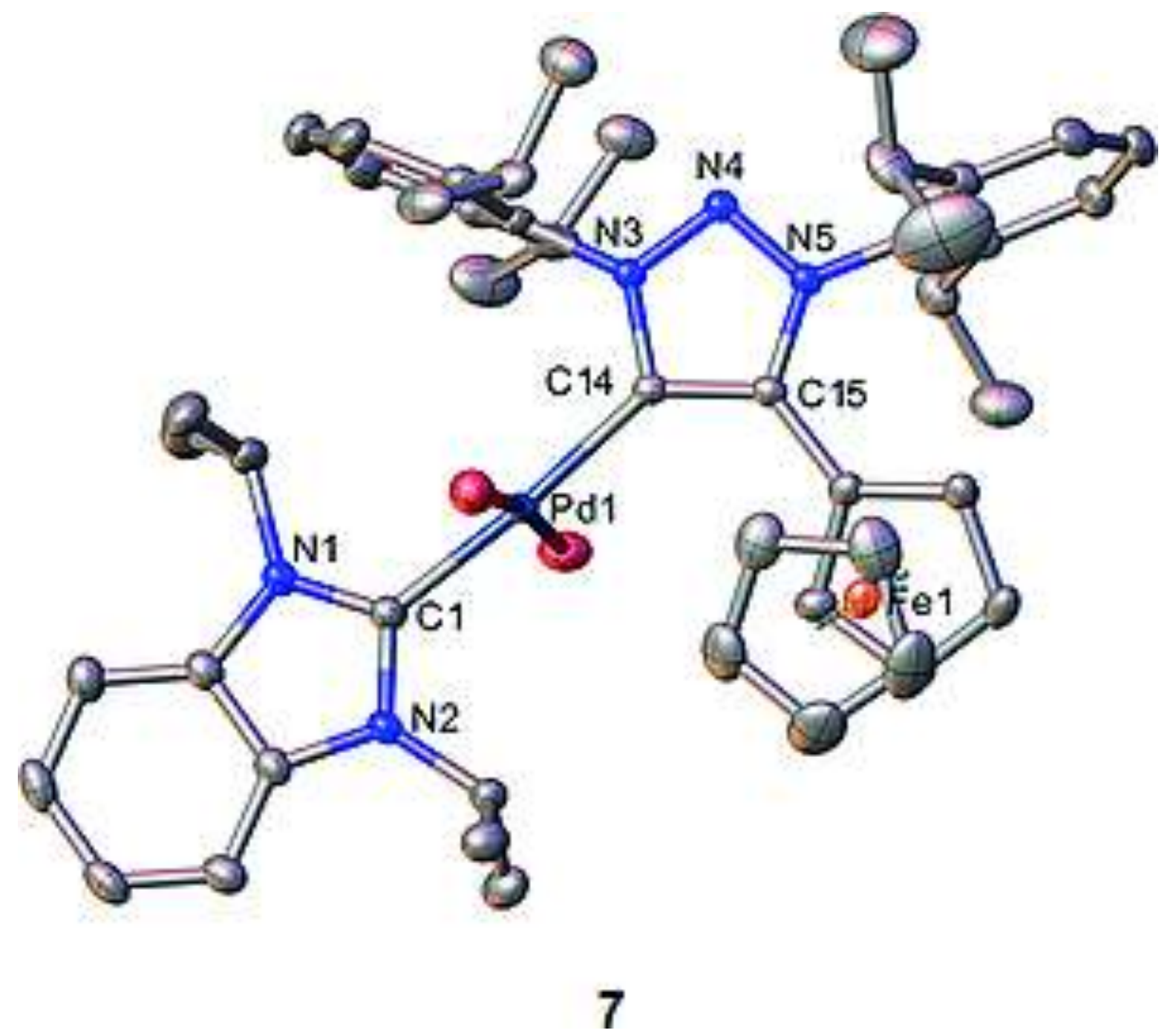

Figure 3. Molecular structure of the PdIl complex 7, showing $50 \%$ probability ellipsoids and partial atomnumbering scheme. Hydrogen atoms are omitted for clarity. Selected bond lengths $[\AA]$ and angles $\left[{ }^{\circ}\right]$ for 7 : Pd1-C1 2.002(2), Pd1-C14 2.0467(19), N3-N4 1.336(2), N4-N5 1.331(2), C15-N5 1.374(2), C14-C15 1.403(3), C14-N3 1.376(2), C1-Pd1-Br1 88.07(6), C1-Pd1-C14 175.44(8), N3-C14-15 101.99(16).

\section{Electrochemical Investigation and Chemical Oxidation}

The electrochemical properties of $\mathbf{A}, \mathbf{1}$ and $\mathbf{4}$ were evaluated by cyclic voltammetry. The cyclic voltammogram (CV) of $\mathbf{A}$ (Figure S27) shows two reversible redox processes, namely the reduction of the triazolium (ring $\mathrm{N}$ atom) and the oxidation of the ferrocenyl moiety at peak potentials of $E^{\circ \prime}=-2.16$ and $0.30 \mathrm{~V}$, respectively (Table 1 ). For $\mathbf{1}$ and $\mathbf{4}$, reversible oxidation of the ferrocenyl groups, and quasi- or irreversible oxidation waves related to the $\mathrm{Rhl} / \mathrm{Il}$ and RhIl/III couples are observed at higher potentials. The values obtained for $\mathbf{1}$ and $\mathbf{4}$ are summarised in Table 1. In the case of $\mathbf{1}$, a two-electron oxidation of Rhl to RhIll is observed at $608 \mathrm{mV}\left(E^{\circ \prime}=533 \mathrm{mV}\right)$, while the $\mathrm{CV}$ of 4 shows two separate rhodium oxidation waves at higher potentials $[\mathrm{Epa}(\mathrm{RhI} / \mathrm{II})=568 \mathrm{mV}, \mathrm{Epa}(\mathrm{RhII} / \mathrm{III})=960 \mathrm{mV}]$, due to the presence of the $\pi$-acidic carbonyl ligands in $\mathbf{4}$, compared with the cod ligand in $\mathbf{1}$. For the Fell/III redox couple of the ferrocenyl group, the electrostatic effect of the cationic triazolium salt results in a more positive potential of the ferrocenyl oxidation event in $\mathbf{A}$ ( $E^{\circ}$ $=0.296 \mathrm{~V}$ ) compared with the potentials of the ferrocenyl group oxidation in the rhodium 
complexes $\left(E^{\circ \prime}=0.029 \mathrm{~V}\right.$ for $1, E^{\circ \prime}=0.105 \mathrm{~V}$ for 4$)$. The effect of the coligands [cod vs. (CO)2], is also reflected in a more positive oxidation potential for $\mathbf{4}$ than for $\mathbf{1}$. The reversibility of the Fell/III couple for all three compounds at room temperature, however, demonstrates the stability of the one-electron oxidation products of $\mathbf{A}, \mathbf{1}$ and $\mathbf{4}$ on the CV timescale. This prompted the chemical oxidation of both the precursor salt and the rhodium complexes. The triazolium salt $\mathbf{A}$ was treated with 1.1 equiv. of the oxidizing agent AgPF6, and the resulting oxidized dicationic salt Aox was isolated (Scheme 3). Single crystals of Aox could be grown from a solution in dichloromethane, and the molecular structure is shown in Figure 2 (bottom). The elongation of the $\mathrm{Fe}-\mathrm{C}(\mathrm{Cp})$ bonds (average $2.089 \AA$ ) of the ferrocenium moiety in Aox also contrasts with the shorter average $\mathrm{Fe}-\mathrm{C}(\mathrm{Cp})$ bond lengths for $\mathbf{A}(2.046 \AA)$ and $\mathbf{A}^{\prime}(2.042 \AA)$, respectively. The bond lengths and angles of the triazol ring in $\mathbf{A}$ and Aox are very similar, and deviate, as expected, from the more acute $\mathrm{N}-$ Ccarbene-N angle of the free carbene $\left[99.6(3)^{\circ}\right.$ for $\mathbf{A}^{\prime}$ compared with $106.00(19)^{\circ}$ and $105.70(2)^{\circ}$ for $\mathbf{A}$ and Aox, respectively) and the longer bonds observed for the triazol ring in $\mathbf{A}^{\prime}$.[6b], [8] The radical dication Aox is $1 \mathrm{H}$ and $13 \mathrm{C}$ NMR spectroscopically silent, although an 19F NMR spectrum could be recorded (Figure S26), showing the upfield shift of the PF6-counterion doublet resonance $[\delta=-85.07(J=969.1 \mathrm{~Hz})$ for Aox vs. $\delta=-72.95(J=706.3 \mathrm{~Hz})$ for A], with the accompanying increase in the coupling constant, as anticipated for the hexafluorophosphate group in a paramagnetic compound.[17] Deprotonation of Aox with KHMDS, followed by coordination to $[\mathrm{Rh}(\operatorname{cod}) \mathrm{Cl}] 2$ forms the radical cation $10 x$ in situ, and after ligand substitution of the cod with carbonyl ligands, the one-electron oxidation product [ $\left.\mathrm{Rh}\left(\mathbf{A}^{\prime} \mathbf{o x}\right) \mathrm{Cl}(\mathrm{CO}) 2\right] \mathrm{PF} 6$ (4ox) could be isolated as a green-brown solid, stable to atmospheric conditions for up to $8 \mathrm{~h}$. Direct oxidation of 4 with the halide-scavenging AgPF6 was not possible. However, the use of acetylferrocenium hexafluorophosphate ([AcFc]PF6, $E^{\circ \prime}=0.27 \mathrm{~V}$ in $\mathrm{CH} 2 \mathrm{Cl} 2$ ), [18] proved a sufficiently strong oxidizing agent to chemically oxidize 1 to $10 x$ (not isolated), which could be treated with excess carbon monoxide to yield $40 x$ in an alternative preparatory route. Recording of NMR spectra for the paramagnetic 4ox was not possible, although the IR stretching frequency of the carbonyl ligands could be measured (Figure S29). The higher-energy absorption bands $(2082,2009 \mathrm{~cm}-1)$ of $40 x$ resulted in a calculated TEP of $2057 \mathrm{~cm}-1$. This shift of $10 \mathrm{~cm}-1$ is consistent with the localization of the positive charge on the terminal ferrocenium group, and not on the RhI centre bonded directly to the carbonyl ligands.[19] However, the high-frequency TEP of 4ox unambiguously confirms the weaker donating ability of the oxidized trz ligand, as expected by the electron-withdrawing nature of the ferrocenium group (almost as electronwithdrawing as a CF3 substituent).[20]

Table 1. Potentials [mV] for the two redox processes observed for $\mathbf{A}, \mathbf{1}$ and $\mathbf{4}$ vs. the $\mathrm{Ag} / \mathrm{Ag}+$ couple, using the redox couple [Fe(n5-C5Me5)2]+1/0 as the internal standard

A

$\begin{array}{ccccc} & \text { trz-H+1/0 } & \text { Fell/III } & \text { Fell/III } & \text { RhI/III[a] } \\ E \text { pa } & -2121 & 336 & 103 & 608 \\ E \mathrm{pc} & -2191 & 256 & -48 & 458 \\ E^{\circ \prime} & -2156 & 296 & 27 & 533 \\ \Delta E \mathrm{p} & 70 & 80 & 55 & 151 \\ \text { ipc/ipa } & 1.11 & 1.07 & 1.02 & 0.89\end{array}$

1

Fell/III
145
65
105
81
0.89

4

$\begin{array}{cc}\text { RhI/II } & \text { RhII/III } \\ 568 & 960 \\ -b & -b \\ -b & -b \\ -b & -b \\ -b & -b\end{array}$

aOverlapping waves of Rhl/II and RhIl/III. 
$b$ Not observed in the solvent window employed.

A
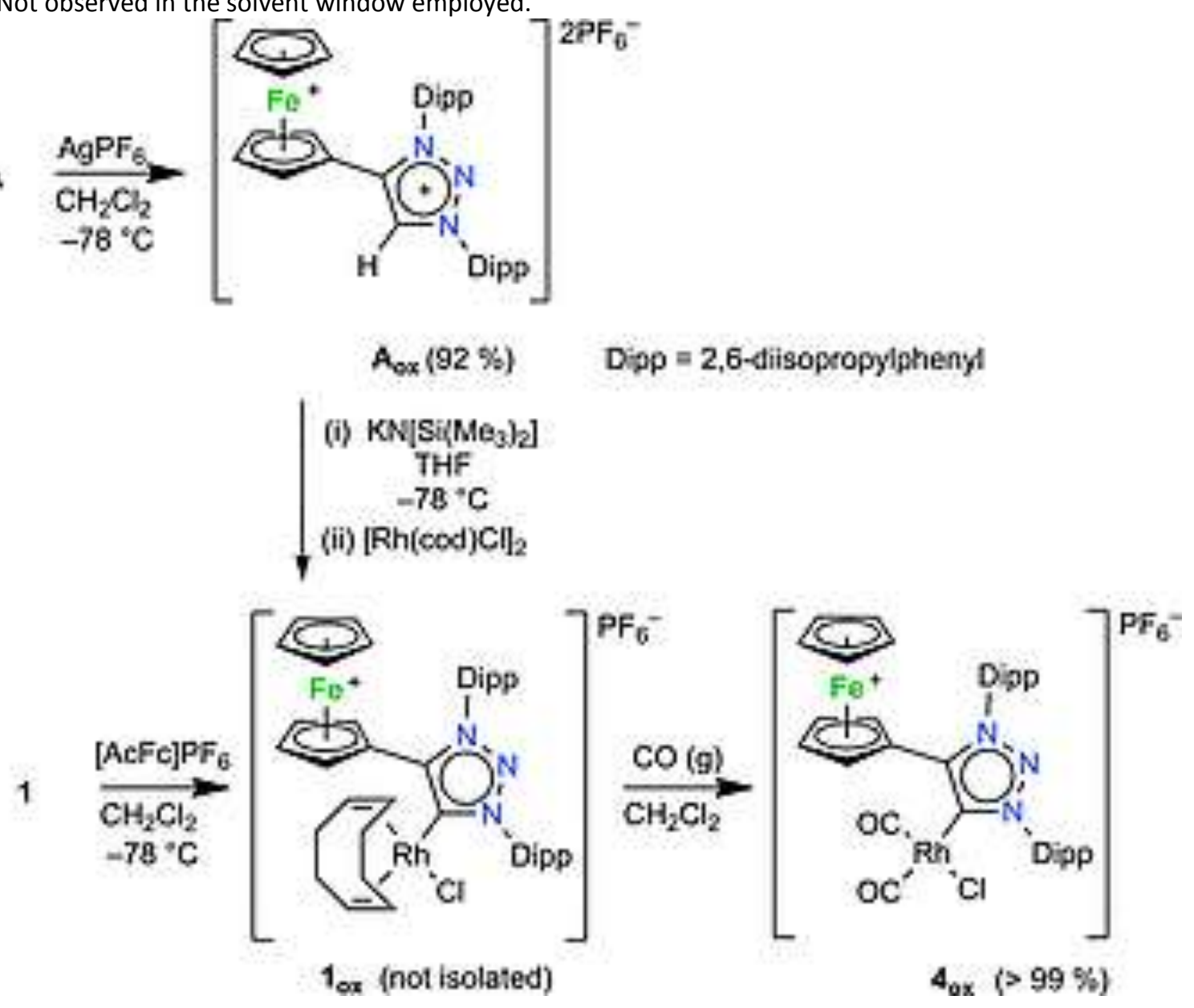

Scheme 3. Chemical oxidation of ligand precursor A and complex 1.

\section{Hydroformylation of 1-Octene}

The replacement of phosphine ligands by the more robust NHC ligands has become an increasingly favoured approach in the design of Rhl hydroformylation catalysts, especially in the effort to preclude the addition of excess phosphines to the reaction mixture.[21] As with their phosphine analogues, it can be shown that NHC ligands that are less electron-donating and sterically more demanding furnish Rh-NHC complexes favouring anti-Markovnikov addition of the substrate olefin to the Rh centre, leading to higher yields of the more desirable linear aldehyde products, compared with the internal alkenes and branched aldehydes of the isomerization products.[22] However, increased activity and chemoselectivity (aldehyde formation) is often forfeited at the cost of decreased regioselectivity ( $n$-aldehyde formation), especially for aliphatic alkene substrates. As such, for RhI-NHC catalyst precursors, high turnover frequencies (TOFs) of 480-3540 h-1 are accompanied by low $n /$ iso-aldehyde ratios $(<0.50)$, while regioselective catalyst precursors with $n$ /iso ratios ranging from 16-27 demonstrated a significant loss in activity (TOFs ranging between 3 and $15 \mathrm{~h}-1$ ).[23] Our idea was to exploit the steric bulk of the triarylated trz-ligand scaffold $\mathbf{A}^{\prime}$, and the significantly lesser electron-donating ability of the oxidized ferrocenium trz ligand ( $\left.\mathbf{A}^{\prime} \mathbf{o x}\right)$, as a strategy to increase the activity of the Rhl catalyst, without concurrent loss in selectivity. 
Complexes 1-3 and 1ox (generated in situ with the addition of the chemical oxidant [AcFc]PF6) were evaluated as catalyst precursors in the hydroformylation of 1-octene. The cod complexes were employed as catalyst precursors, as the first step in the hydroformylation catalytic cycle is the substitution of the cod moiety by carbonyl ligands.[24] The reaction conditions for 1 were optimized by variation of the syngas pressure (30-50 bar), temperature $\left(55-95^{\circ} \mathrm{C}\right)$, reaction time $(4-8 \mathrm{~h})$ and catalyst loading $(0.04-0.08$ mol-\%) (Table S1). Under the optimized conditions of $40 \mathrm{bar}, 75^{\circ} \mathrm{C}, 8 \mathrm{~h}$ and $0.08 \mathrm{~mol}-\%$ catalyst loading, the catalyst precursors displayed good to excellent conversions (95.83$99.9 \%$ ) of 1-octene after $8 \mathrm{~h}$ (Table 2). A mercury drop-test was performed on catalyst 1 with no resulting significant change in either the conversion or selectivity of the catalyst, thereby indicating that a heterogeneous catalytic mode of action can be excluded.[25] Additionally, the precursor triazolium salt $\mathbf{A}$ was shown to be catalytically inactive. For the neutral complexes 1-3, the more electron-deficient and sterically hindered 1 proved the most regioselective with an $n$ /iso ratio of 2.43 , but less active [TOF $=99.73(7.07) \mathrm{h}-1$ and $95.83 \%$ conversion] than the N3-alkylated $\mathbf{2}$ and $\mathbf{3}$ [ $n /$ iso $=1.79$ and 1.75 ; conversions $>$ $99.9 \%$; and TOF $=125.20$ and 116.83(5.20) h-1, respectively]. Precatalysts 2 and $\mathbf{3}$ displayed very similar behaviour, indicating in this case, the greater effect of N3-substitution than C4substitution. The addition of the oxidant acetylferrocenium to generate 1ox in situ resulted in a significant change in the reactivity, compared with $\mathbf{1}$. As anticipated, better activity was achieved [conversion > 99.9\%; TOF $=118.95(3.67) \mathrm{h}-1$ ], as well as increased chemoselectivity [76.13(2.35) \% aldehyde yield]. Surprisingly, however, the regioselectivity resulting from the sterically more demanding triarylated trz ligand was not retained, with an $n /$ iso-aldehyde ratio of 1.60 , which was significantly reduced, compared with 1 .

Table 2. Hydroformylation of 1-octene with catalyst precursors 1-3a and 1oxb

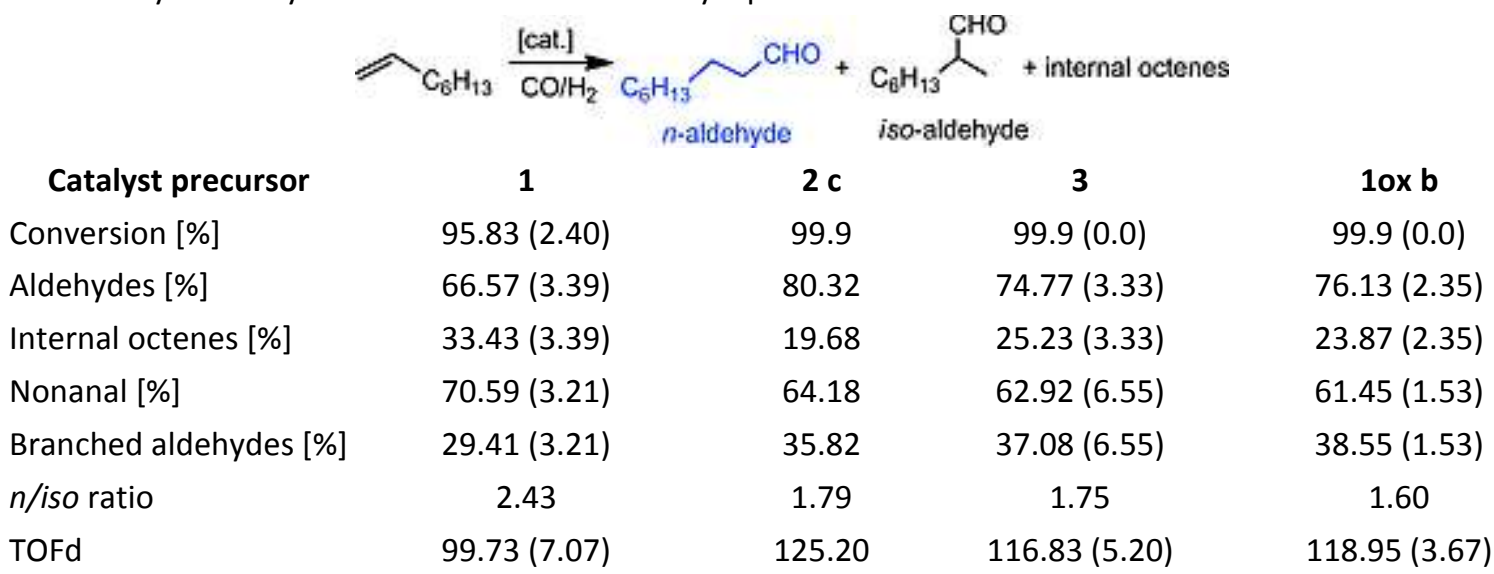

aReactions were carried out with $\mathrm{CO} / \mathrm{H} 2(1: 1)$ at 40 bar, $75^{\circ} \mathrm{C}$ in toluene $(5 \mathrm{~mL})$ with $6.37 \mathrm{mmol}$ of 1-octene and $0.0078 \mathrm{mmol}$ of Rh catalyst ( $0.08 \mathrm{~mol}-\%$ catalyst loading). After $8 \mathrm{~h}$, the GC conversions were obtained using $n$-decane as an internal standard in relation to authentic standard internal isooctene and aldehyde standards. Reactions were performed in triplicate, and the standard deviations are given in parentheses for all results.

$b 10 x$ was generated in situ by the addition of $0.0086 \mathrm{mmol}$ of [AcFc]PF6 to $0.0078 \mathrm{mmol}$ of 1 .

cSingle catalytic run.

$d T O F=($ mol aldehyde/mol cat. $) \mathrm{h}-1$. 


\section{Conclusion}

The isolation and characterization of a new triarylated mesoionic carbene $\mathbf{A}^{\prime}$ with a $\mathbf{C} 4$ ferrocenyl group was achieved, and the use of the $13 C$ NMR spectroscopic probe carbene to evaluate the chemical shift of the complex $\left[\mathrm{Pd}(i \mathrm{Pr} 2-\operatorname{bimy})(\mathrm{Br}) 2\left(\mathbf{A}^{\prime}\right)\right](\mathbf{7})$ confirmed the weaker donating ability of this trz ligand, compared with known N3-alkylated triazolylidenes. RhI-cod and dicarbonyl complexes 1-6 featuring $A^{\prime}$, and the related N3alkylated $\mathbf{B}^{\prime}$ and $\mathbf{C}^{\prime}$ trz ligands, were prepared, and their steric and electronic properties were compared. The reversibility of the Fell/III couple of the ferrocenyl moiety in A, 1 and $\mathbf{4}$ leads to the chemical oxidation of these compounds in an attempt to further decrease the electron-donating ability of $\mathbf{A}^{\prime}$. The use of either AgPF6 or [AcFc]PF6 as oxidant resulted in the isolation of the dicationic ferrocenium triazolium salt Aox and the radical cation 4ox, for which the high-frequency TEP confirmed the electron-withdrawing effect of the ferrocenium substituent. The complexes 1-3 and 10x were screened as catalyst precursors for the hydroformylation of 1-octene. Excellent conversion of the substrate olefin was observed, with turnover frequencies and chemo- and regioselectivities toward linear aldehydes comparable with some of the best results reported for earlier Rh-nNHC complexes. The approach of using the redox activity of the Fc substituent to significantly improve the catalyst performance as a redox-switchable catalyst, as demonstrated for related Aulferrocenyl-triazolylidene complexes,[2e] proved only partially successful. Although an improvement in the activity and chemoselectivity followed the addition of oxidant to the precursor catalyst $\mathbf{1}$, a significant reduction in the regioselectivity was observed. Undoubtedly, both steric and electronic effects play a role with regards to the catalyst performance, although the contributions of each cannot be unambiguously separated.

\section{Experimental Section}

General: All air- and moisture-sensitive synthetic procedures were performed under N2(g) or $\operatorname{Ar}(\mathrm{g})$ using standard Schlenk techniques. All solvents were purified and distilled from $\mathrm{Na}$ (s) (hexane, diethyl ether, benzene and THF) or $\mathrm{CaH} 2$ (dichloromethane and acetonitrile) under N2(g). Ethynylferrocene,[26] 1,3-bis(2,6-diisopropylphenyl)triaz-1-ene (triazene),[27]

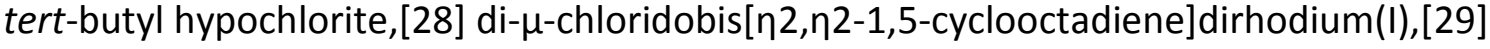
triethyloxonium tetrafluoroborate,[30] and acetylferrocenium hexafluorophosphate[31] were synthesized according to previously reported literature methods. All other reagents were commercially available and used without any purification thereof. Air-sensitive solids were stored and handled in a Purelab HE glovebox. A Bruker AVANCE III $300.12 \mathrm{MHz}$ or 400.21 MHz spectrometer was used for NMR spectroscopic experiments. Chemical shifts are reported as $\delta$ (in ppm) and reported relative to the deuterated solvent signal: for $\mathrm{CDCl} 3$, C6D6 and $\mathrm{CD} 3 \mathrm{CN}, \delta \mathrm{H}$ was at $\delta=7.26,7.16$ and $1.94 \mathrm{ppm}$, respectively, and $\delta \mathrm{C}$ was at $\delta=$ $77.16,128.10$ and $118.26 \mathrm{ppm}$, respectively. 31P $\{1 \mathrm{H}\} \mathrm{NMR}$ spectra were referenced to the deuterated lock solvent, which had been referenced to $85 \%$ H3PO4. Solution FT-IR spectra $[v(\mathrm{CO})]$ were recorded with a Bruker ALPHA FT-IR spectrophotometer with an $\mathrm{NaCl}$ cell (path length of ca. $1.0 \mathrm{~mm}$ ), using $\mathrm{CH} 2 \mathrm{Cl} 2$ as the solvent. The range of absorption measured was from 4000 to $600 \mathrm{~cm}-1$. Mass spectrometric analyses were performed with a Waters Synapt G2 HDMS by direct infusion at $5 \mu \mathrm{L}$ min-1, with positive electron spray as the ionization technique, for $3 \mathrm{~min}$. The $\mathrm{m} / \mathrm{z}$ values were measured in the range of 50-2000 in acetonitrile. Prior to analysis, sodium formate $(5 \mathrm{~mm})$ was used to calibrate the instrument in resolution 
mode. Elemental analyses were carried out with a Thermo Flash 1112 Series CHNS-O Analyzer. Melting points were measured with a Stuart SMP10 melting point apparatus.

Preparation of the Free Carbene 1,3-Bis(2,6-diisopropylphenyl)-4-ferrocenyl-1,2,3-triazol5-ylidene $\left(\mathbf{A}^{\prime}\right)$ : THF $(5 \mathrm{~mL})$ was added to a mixture of $\mathbf{A}(84 \mathrm{mg}, 0.18 \mathrm{mmol})$ and KOtBu (17 $\mathrm{mg}, 0.15 \mathrm{mmol}$ ) at $0{ }^{\circ} \mathrm{C}$. The mixture was subsequently stirred at $0{ }^{\circ} \mathrm{C}$ for $30 \mathrm{~min}$ and at room temperature for $1 \mathrm{~h}$. The solvent was removed under reduced pressure, and the remaining solid was extracted with hexane $(10 \mathrm{~mL})$. Removal of the solvent in vacuo afforded $\mathbf{A}^{\prime}$ as a red powder. Single crystals were obtained by storing a concentrated solution of $A^{\prime}$ in hexane at $-30{ }^{\circ} \mathrm{C}$ overnight. Yield: $67 \%$ (45 mg, $0.08 \mathrm{mmol}$ ). $1 \mathrm{H} \mathrm{NMR} \mathrm{(400} \mathrm{MHz,} \mathrm{C6D6):} \delta=7.34-$ $7.19(\mathrm{~m}, 4 \mathrm{H}, \operatorname{dipp}-\mathrm{H}, 1-\mathrm{H}), 7.07(\mathrm{~d}, 3 J=7.7 \mathrm{~Hz}, 2 \mathrm{H}$, dipp-H, 2-H), 4.61 (t, J=1.8 Hz, $2 \mathrm{H}, \mathrm{Fc}-\mathrm{H}$, 3-H), $4.21(\mathrm{~s}, 5 \mathrm{H}, \mathrm{Fc}-\mathrm{H}, 4-\mathrm{H}), 3.93(\mathrm{t}, \mathrm{J}=1.8 \mathrm{~Hz}, 2 \mathrm{H}, \mathrm{Fc}-\mathrm{H}, 5-\mathrm{H}), 3.04(\mathrm{sept}, 3 \mathrm{JHH}=6.8 \mathrm{~Hz}, 2 \mathrm{H}$, $\operatorname{dipp}[$ iso]-CH, 6-H), 2.66 (sept, $3 J=6.8 \mathrm{~Hz}, 2 \mathrm{H}$, dipp[iso]-CH, 6-H), 1.38 (d, $3 \mathrm{~J}=6.8 \mathrm{~Hz}, 6 \mathrm{H}$, dipp[iso]-CH3 7-H), 1.22 (d, 3J =6.8 Hz, $6 \mathrm{H}$, dipp[iso]-CH3, 7-H), 1.11 (d, 3J = 6.8 Hz, $6 \mathrm{H}$, dipp[iso]-CH3, 7-H), 1.09 (d, 3J = 6.8 Hz, $6 \mathrm{H}$, dipp[iso]-CH3, 7-H) ppm. 13C $\{1 \mathrm{H}\}$ NMR (101 $\mathrm{MHz}, \mathrm{C6D6}$ ): $\delta=201.7$ (Cq, Ccarbene, C-1), 149.7 (dipp-Cq, C-2), 146.0 (dipp-Cq, C-3), 145.5 (dipp-Cq, C-3), 139.5 (dipp-Cq, C-2), 133.6 (trz-Cq, C-4), 131.0 (dipp-CH, C-5), 129.8 (dipp-CH, C-5), 124.4 (dipp-CH, C-6), 123.7 (dipp-CH, C-6), 76.6 (Fc-Cq, C-7), 70.6 (Fc-CH, C-8), 69.3 (FcCH, C-9), 69.1 (Fc-CH, C-9), 29.1 (dipp[iso]-CH, C-10), 29.0 (dipp[iso]-CH, C-10), 25.2 (dipp[iso]-CH3, C-11), 24.5 (dipp[iso]-CH3, C-11), 24.2 (dipp[iso]-CH3, C-11), 23.0 (dipp[iso]$\mathrm{CH} 3, \mathrm{C}-11) \mathrm{ppm}$.

\section{Preparation of 1,3-Bis(2,6-diisopropylphenyl)-4-ferrocenium-1H-1,2,3-triazolium}

Hexaflourophosphate (Aox): AgPF6 (0.04 g, $0.15 \mathrm{mmol}, 1.1$ equiv.) was added to a solution of $\mathbf{A}(0.1 \mathrm{~g}, 0.14 \mathrm{mmol})$ in deoxygenated $\mathrm{DCM}(15 \mathrm{~mL})$ at $-78^{\circ} \mathrm{C}$, in the absence of light. The solution underwent a colour change, from orange to green, and was stirred at room temperature for $1 \mathrm{~h}$. The reaction mixture was filtered and the solvent evaporated; the resultant solid was obtained in quantitative yield and stored in a glovebox.

Aox: Green-brown powder. Yield: $0.11 \mathrm{~g}(92 \%) .19 \mathrm{~F}\{1 \mathrm{H}\} \mathrm{NMR}(282 \mathrm{MHz}, \mathrm{CD} 2 \mathrm{Cl} 2): \delta=-$ 85.07 (d, $J=969.09 \mathrm{~Hz}$, PF6) ppm.

Preparation of Complex 1: Triazolium salt A $(0.50 \mathrm{~g}, 0.69 \mathrm{mmol})$ and $\mathrm{KN}(\mathrm{SiMe}) 2(0.15 \mathrm{~g}$, $0.76 \mathrm{mmol}$ ) were added to a purged Schlenk vessel. The solid reactants were dissolved in THF (ca. $30 \mathrm{~mL}$ ), cooled to $-78^{\circ} \mathrm{C}$ and stirred for $10 \mathrm{~min}$. At $-78{ }^{\circ} \mathrm{C}$, the solution was added to $[\mathrm{Rh}(\mathrm{cod}) \mathrm{Cl}] 2(0.17 \mathrm{~g}, 0.35 \mathrm{mmol}, 0.5$ equiv.) dissolved in THF $(15 \mathrm{~mL})$. The reaction mixture was stirred overnight and warmed up to room temperature. The solvent was evaporated under reduced pressure, followed by extraction with anhydrous toluene and washing with hexane to afford the complex 1 as an orange powder.

\section{[1,3-Bis(2,6-diisopropylphenyl)-4-ferrocenyl-1,2,3-triazol-5-ylidene]chlorido(n4-1,5-} cyclooctadiene)rhodium(I) [Rh(A')Cl(cod)] (1): Orange powder. Yield: $0.47 \mathrm{~g}(83 \%)$. M.p. 240-250 ${ }^{\circ} \mathrm{C}$ (decomp). $1 \mathrm{H} \mathrm{NMR} \mathrm{(400} \mathrm{MHz,} \mathrm{CDCl3):} \delta=7.57$ (dt, $J=12.0,7.8 \mathrm{~Hz}, 2 \mathrm{H}$, dipp-CH, 1-H), 7.50 (dd, J = 7.8, 1.3 Hz, $1 \mathrm{H}$, dipp-CH, 2-H), 7.40 (dd, J= 7.8, 1.2 Hz, $1 \mathrm{H}$, dipp-CH, 2-H), $7.28(\mathrm{dd}, J=1.33,2.83 \mathrm{~Hz}, 2 \mathrm{H}$, dipp-CH, 2-H), $6.98(\mathrm{~m}, 1 \mathrm{H}, \mathrm{Fc}-\mathrm{H}, 3-\mathrm{H}), 5.02(\mathrm{~m}, 1 \mathrm{H}, \mathrm{cod}-\mathrm{CH}$, 6-H), $4.80(\mathrm{~m}, 1 \mathrm{H}$, cod-CH, 6-H), $4.50(\mathrm{~m}, 1 \mathrm{H}, \mathrm{Fc}-\mathrm{H}, 3-\mathrm{H}), 4.11(\mathrm{~m}, 6 \mathrm{H}, \mathrm{Fc}-\mathrm{H}, 4-\mathrm{H}+5-\mathrm{H}), 3.93$ ( $m, 1 \mathrm{H}$, cod-CH, 6-H), 3.82-3.71 (m, $2 \mathrm{H}, \mathrm{Fc}-\mathrm{H}, 4$ and cod-H-CH, 6-H), 3.09 (m, $1 \mathrm{H}, \mathrm{cod}-\mathrm{CH} 2$, 
7-H), 2.89 (m, $1 \mathrm{H}$, dipp[iso]-CH, 8-H), 2.56 (m, $1 \mathrm{H}$, cod-CH2, 8-H), 2.44 (m, $1 \mathrm{H}$, cod-CH2, 7H), $2.25(\mathrm{~m}, 1 \mathrm{H}$, dipp[iso]-CH, 8-H), $2.06(\mathrm{~m}, 1 \mathrm{H}$, dipp[iso]-CH, 8-H), $1.92(\mathrm{~m}, 4 \mathrm{H}, \mathrm{cod}-\mathrm{CH} 2$, 7-H), $1.68(\mathrm{~m}, 2 \mathrm{H}, \mathrm{cod}-\mathrm{CH} 2,7-\mathrm{H}), 1.58(\mathrm{t}, J=6.6 \mathrm{~Hz}, 3 \mathrm{H}$, dipp[iso]-CH3, 9-H), $1.55(\mathrm{~m}, 2 \mathrm{H}$, $\operatorname{dipp}[$ iso]-CH, 9-H), 1.51 (d, J = 6.8 Hz, $3 \mathrm{H}$, dipp[iso]-CH3, 9-H), 1.28 (d, J=6.8 Hz, $3 \mathrm{H}$, $\operatorname{dipp}[$ iso]-CH3, 9-H), 1.21 (d, J = 6.8 Hz, $6 \mathrm{H}$, dipp[iso]-CH3, 9-H), 1.03 (d, J=6.9 Hz, $3 \mathrm{H}$, $\operatorname{dipp}[$ iso]-CH3, 9-H), $0.92(\mathrm{~d}, J=6.8 \mathrm{~Hz}, 3 \mathrm{H}$, dipp[iso]-CH3, 9-H), 0.79 (d, J = 6.6 Hz, $3 \mathrm{H}$, dipp[iso]-CH3, 9-H) ppm. 13C $\{1 \mathrm{H}\}$ NMR (101 MHz, CDCl3): $\delta=171.9$ (d, JRhC $=46.6 \mathrm{~Hz}$, Ccarbene, C-1), 149.9 (trz-Cq, C-2), 147.6 (dipp-Cq, C-3), 147.4 (dipp-Cq, C-3), 145.4 (dippCq, C-3), 144.8 (dipp-Cq, C-3), 136.0 (dipp-Cq, C-4), 133.1 (dipp-Cq, C-4), 131.5 (dipp-CH, C5), 130.8 (dipp-CH, C-5), 125.5 (dipp-CH, C-6), 124.7 (dipp-CH, C-6), 123.9 (dipp-CH, C-6), 122.9 (dipp-CH, C-6), 94.7 (d, J=7.7 Hz, cod-CH, C-7), 93.7 (d, J = 7.7 Hz, cod-CH, C-7), 73.8 (Fc-Cq, C-8), 73.2 (Fc-CH, C-9), 69.8 (Fc-CH, C-9), 69.7 (Fc-CH, C-11), 69.2 (d, J=14.5 Hz, cod$\mathrm{CH}, \mathrm{C}-7$ ), 68.9 (Fc-CH, C-10), 66.6 (d, J = 14.3 Hz, cod-CH, C-7), 66.2 (Fc-CH, C-10), 33.6 (cod$\mathrm{CH} 2, \mathrm{C}-12$ ), 32.5 (cod-CH2, C-12), 29.2 (dipp[iso]-CH, C-13), 29.1 (cod-CH2, C-12), 29.0 (dipp[iso]-CH, C-13), 28.9 (dipp[iso]-CH, C-13), 28.8 (cod-CH2, C-12), 28.3 (dipp[iso]-CH, C13), 26.5 (dipp[iso]-CH3, C-14), 26.4 (dipp[iso]-CH3, C-14), 26.4 (dipp[iso]-CH3, C-14), 25.6 (dipp[iso]-CH3, C-14), 25.1 (dipp[iso]-CH3, C-14), 25.0 (dipp[iso]-CH3, C-14), 24.2 (dipp[iso]$\mathrm{CH} 3, \mathrm{C}-14$ ), 23.6 (dipp[iso]-CH3, C-14), 23.4 (dipp[iso]-CH3, C-14), 23.3 (dipp[iso]-CH3, C-14), 23.1 (dipp[iso]-CH3, C-14) ppm. C44H545ClFeN3Rh (with 0.3 equiv. H2O; 820.13): calcd. C 62.38, H 6.54, N 4.96; found C 62.68, H 6.67, N 4.71. ESI-HRMS (15 V, positive mode): calcd. for $[\mathrm{M}-\mathrm{Cl}]+784.2800$; found 784.2834 .

Preparation of Complexes $\mathbf{2}$ and 3: The appropriate triazolium salt $\mathbf{B}$ or $\mathbf{C}(0.75 \mathrm{mmol})$ was weighed, along with excess $\mathrm{KN}(\mathrm{SiMe} 3) 2(0.16 \mathrm{~g}, 0.83 \mathrm{mmol})$ and $[\mathrm{Rh}(\mathrm{cod}) \mathrm{Cl}] 2(0.18 \mathrm{~g}, 0.38$ mmol, 0.5 equiv.) in a Schlenk tube purged with argon gas. The solid mixture was cooled down to $-78{ }^{\circ} \mathrm{C}$, and cooled THF (ca. $10 \mathrm{~mL}$ ) was added. The reaction mixture was stirred overnight, while warming up to room temperature. The solvent was evaporated under reduced pressure. Following extraction with anhydrous toluene and washing with hexane, complex $\mathbf{2}$ was afforded as an orange powder and complex $\mathbf{3}$ as a yellow powder.

[1-Ethyl-3-(2,6-diisopropylphenyl)-4-ferrocenyl-1,2,3-triazol-5-ylidene]chlorido(n4-1,5cyclooctadiene)rhodium(I) [Rh(B') Cl(cod)] (2): Orange powder. Yield: $0.31 \mathrm{~g}(59 \%)$. M.p. 155-158 ${ }^{\circ} \mathrm{C} .1 \mathrm{H}$ NMR $(300 \mathrm{MHz}, \mathrm{CDCl} 3): \delta=7.55(\mathrm{t}, J=7.7 \mathrm{~Hz}, 1 \mathrm{H}, \operatorname{dipp}-\mathrm{CH}, 1-\mathrm{H}), 7.46(\mathrm{~d}, J=$ $7.6 \mathrm{~Hz}, 1 \mathrm{H}, \operatorname{dipp}-\mathrm{CH}, 2-\mathrm{H}), 7.26(\mathrm{~d}, J=7.4 \mathrm{~Hz}, 1 \mathrm{H}, \operatorname{dipp}-\mathrm{CH}, 2-\mathrm{H}), 5.85(\mathrm{~m}, 1 \mathrm{H}, \mathrm{Fc}-\mathrm{CH}, 3-\mathrm{H})$, $5.77(\mathrm{~m}, 1 \mathrm{H}, \mathrm{Fc}-\mathrm{CH}, 3-\mathrm{H}), 4.92(\mathrm{dd}, J=13.7,7.2 \mathrm{~Hz}, 1 \mathrm{H},-\mathrm{CH} 2 \mathrm{CH} 3,4-\mathrm{H}), 4.80$ (br., $2 \mathrm{H}, \mathrm{cod}-$ $\mathrm{CH}, 5-\mathrm{H}), 4.69$ (dd, J = 13.7, 7.2 Hz, $1 \mathrm{H},-\mathrm{CH} 2 \mathrm{CH} 3,4-\mathrm{H}), 4.54(\mathrm{~m}, 2 \mathrm{H}, \mathrm{Fc}-\mathrm{CH}, 6-\mathrm{H}), 4.24(\mathrm{~m}, 5$ $\mathrm{H}, \mathrm{Fc}-\mathrm{CH}, 7-\mathrm{H}), 3.62(\mathrm{~m}, 1 \mathrm{H}$, dipp[iso]-CH, 8-H), $3.40(\mathrm{~m}, 1 \mathrm{H}, \mathrm{cod}-\mathrm{CH}, 5-\mathrm{H}), 2.80(\mathrm{~m}, 1 \mathrm{H}$, cod$\mathrm{CH}, 5-\mathrm{H}), 2.46(\mathrm{~m}, 2 \mathrm{H}$, dipp[iso]-CH, 8-H), $2.17(\mathrm{~m}, 2 \mathrm{H}, \mathrm{cod}-\mathrm{CH} 2,9-\mathrm{H}), 1.98-1.61(\mathrm{~m}, 6 \mathrm{H}$, cod-CH2, 9-H), 1.71 (t, $J=7.3 \mathrm{~Hz}, 3 \mathrm{H},-\mathrm{CH} 2 \mathrm{CH} 3,10-\mathrm{H}$ ), 1.51 (d, $J=6.2 \mathrm{~Hz}, 3 \mathrm{H}$, dipp[iso]-CH3, 11-H), 1.42 (m, $3 \mathrm{H}$, cod-CH2, 9-H), 1.16 (d, J = 6.8 Hz, $6 \mathrm{H}$, dipp[iso]-CH3, 11-H), 1.00 (d, J = $6.9 \mathrm{~Hz}, 3 \mathrm{H}$, dipp[iso]-CH3, 11-H) ppm. 13C $\{1 \mathrm{H}\}$ NMR $(75 \mathrm{MHz}, \mathrm{CDCl} 3): \delta=172.3$ (d, JRhC $=$ $47.1 \mathrm{~Hz}$, Ccarbene, C-1), 147.3 (dipp-Cq, C-2), 145.3 (dipp-Cq, C-2), 143.9 (trz-Cq, C-3), 136.7 (dipp-Cq, C-4), 130.7 (dipp-CH, C-5), 124.6 (dipp-CH, C-6), 122.9 (dipp-CH, C-6), 96.2 (d, J = $7.2 \mathrm{~Hz}$, cod-CH, C-7), 93.8 (d, J = 7.81 Hz, cod-CH, C-7), 72.5 (Fc-Cq, C-8), 70.9 (Fc-CH, C-9), 69.9 (Fc-CH, C-9), 69.6 (Fc-CH, C-10), 66.8 (cod-CH, C-7), 66.6 (cod-CH, C-7), 46.1 (-CH2CH3, C-11), 34.4 (dipp[iso]-CH, C-12), 31.2 (cod-CH2, C-13), 29.9 (cod-CH2, C-13), 29.2 (cod-CH2, C-13), 28.8 (dipp[iso]-CH, C-12), 27.9 (cod-CH2, C-13), 26.7 (dipp[iso]-CH3, C-14), 25.9 
(dipp[iso]-CH3, C-14), 23.3 (dipp[iso]-CH3, C-14), 22.4 (dipp[iso]-CH3, C-14), 14.9 (-CH2CH3, C-15) ppm. ESI-HRMS (15 V, positive mode): calcd. for [M - Cl]+652.1861; found 652.1918.

[1-Ethyl-3-(2,6-diisopropylphenyl)-4-phenyl-1,2,3-triazol-5-ylidene]chlorido(n4-1,5cyclooctadiene)rhodium(I) [Rh( $\left.\left.\mathbf{C}^{\prime}\right) \mathbf{C l}(\mathbf{c o d})\right]$ (3): Yellow powder. Yield: $0.07 \mathrm{~g}$ (30\%). M.p. 145 ${ }^{\circ} \mathrm{C}$ (decomp.). $1 \mathrm{H} \mathrm{NMR} \mathrm{(300} \mathrm{MHz,} \mathrm{CDCl3):} \delta=8.09$ (d, J = $7.38 \mathrm{~Hz}, 1 \mathrm{H}$, dipp-CH, 1-H), 7.56 (dt, J=12.6, 6.5 Hz, $5 \mathrm{H}, \mathrm{ph}-\mathrm{CH}, 2-\mathrm{H}), 7.44(\mathrm{~m}, 1 \mathrm{H}, \operatorname{dipp}-\mathrm{CH}, 3-\mathrm{H}), 4.66(\mathrm{~m}, 2 \mathrm{H}, \mathrm{cod}-\mathrm{CH}, 4-\mathrm{H})$, $4.40(\mathrm{~m}, 2 \mathrm{H},-\mathrm{CH} 2 \mathrm{CH} 3,5-\mathrm{H}), 3.45(\mathrm{~m}, 1 \mathrm{H}$, dipp[iso]-CH, 6-H), $3.23(\mathrm{~m}, 1 \mathrm{H}, \operatorname{dipp}[$ iso]-CH, 6$\mathrm{H}), 2.90(\mathrm{~m}, 1 \mathrm{H}, \mathrm{cod}-\mathrm{CH}, 4-\mathrm{H}), 2.00(\mathrm{~m}, 4 \mathrm{H}$, cod-CH, 4-H + cod-CH2, 7-H), $1.63(\mathrm{~m}, 8 \mathrm{H}, \mathrm{cod}-$ $\mathrm{CH} 2,7-\mathrm{H}), 1.50(\mathrm{~m}, 3 \mathrm{H},-\mathrm{CH} 2 \mathrm{CH} 3,8-\mathrm{H}), 1.19-1.04(\mathrm{~m}, 12 \mathrm{H}$, dipp[iso]-CH3, 9-H) ppm. 13C NMR $(75 \mathrm{MHz}, \mathrm{CDCl} 3): \delta=173.2(\mathrm{~d}, \mathrm{JRhC}=47.3 \mathrm{~Hz}$, Ccarbene, C-1), 145.8 (trz-Cq, C-2), 144.9 (dipp-Cq, C-3), 136.3 (dipp-Cq, C-4), 130.9 (ph-CH, C-6), 130.7 (dipp-Cq, C-5), 129.6 (ph-CH, C-6), 128.9 (ph-CH, C-6), 128.5 (dipp-CH, C-7), 124.9 (ph-Cq, C-8), 95.5 (cod-CH, C-9), 70.8 (cod-CH, C-9), 45.6 (-CH2CH3, C-10), 33.4 (cod-CH2, C-11), 32.2 (cod-CH2, C-11), 31.1 (dipp[iso]-CH, C-12), 29.0 (cod-CH2, C-11 + dipp-CH3, C-13), 28.3 (cod-CH2, C-11), 26.6 (dipp-CH3, C-13), 24.8 (dipp-CH3, C-13), 23.7 (dipp-CH3, C-13), 14.9 (-CH2CH3, C-14) ppm. ESI-HRMS (15 V, positive mode): calcd. for [M - Cl]+ 544.2199; found 544.2197.

Preparation of Complexes 4-6: The appropriate (1,2,3-triazol-5-ylidene)chlorido(n4-1,5cyclooctadiene) complex (1: $0.61 \mathrm{mmol} ; 2: 0.15 \mathrm{mmol}$; 3: $0.08 \mathrm{mmol}$ ) was dissolved in $\mathrm{CH} 2 \mathrm{Cl} 2(10 \mathrm{~mL})$, and gaseous $\mathrm{CO}$ was passed through the solution for $10-20 \mathrm{~min}$. The solvent was evaporated, and the residue was washed with hexane. The solid was dried overnight, affording $\mathbf{4}$ and $\mathbf{5}$ as orange powders and $\mathbf{6}$ as a light-yellow powder.

\section{[1,3-Bis(2,6-diisopropylphenyl)-4-ferrocenyl-1,2,3-triazol-5-}

ylidene]chloridodicarbonylrhodium(I) $\left[\operatorname{Rh}\left(\mathrm{A}^{\prime}\right) \mathrm{Cl}(\mathrm{CO}) 2\right](4):$ Orange powder. Yield: $0.41 \mathrm{~g}$ (87\%). M.p. $199^{\circ} \mathrm{C}$ (decomp.) $1 \mathrm{H} \mathrm{NMR}(400 \mathrm{MHz}, \mathrm{CDCl} 3): \delta=7.58$ (t, J $=7.8 \mathrm{~Hz}, 2 \mathrm{H}$, dipp$\mathrm{CH}, 1-\mathrm{H}), 7.40(\mathrm{~m}, 3 \mathrm{H}, \operatorname{dipp}-\mathrm{CH}, 2-\mathrm{H}), 7.29(\mathrm{~m}, 1 \mathrm{H}$, dipp- $\mathrm{CH}, 2-\mathrm{H}), 5.74(\mathrm{~m}, 1 \mathrm{H}, \mathrm{Fc}-\mathrm{H}, 3-\mathrm{H})$, 4.35 (m, 1 H, Fc- H, 3-H), 4.23 (m, 4 H, Fc-H, 5-H), 4.14 (m, 1 H, Fc- H, 4-H), 3.86 (m, 1 H, Fc$\mathrm{CH}, 4-\mathrm{H}), 2.93(\mathrm{dt}, J=13.4,6.7 \mathrm{~Hz}, 1 \mathrm{H}$, dipp[iso]-CH, 6-H), 2.65 (dtd, $J=20.2,13.6,6.8 \mathrm{~Hz}, 2$ $\mathrm{H}$, dipp[iso]-CH, 6-H), 2.19 (dt, J=13.6, $6.8 \mathrm{~Hz}, 1 \mathrm{H}$, dipp[iso]-CH, 6-H), 1.45 (d, J = 6.7 Hz, 3 $\mathrm{H}$, dipp[iso]-CH3, 7-H), 1.37 (dd, $J=6.7,4.8 \mathrm{~Hz}, 6 \mathrm{H}$, dipp[iso]-CH3, 7-H), 1.25 (d, $J=6.8 \mathrm{~Hz}, 3$ $\mathrm{H}$, dipp[iso]-CH3, 7-H), 1.19 (t, $J=6.2 \mathrm{~Hz}, 3 \mathrm{H}$, dipp[iso]-CH3, 7-H), 1.02 (dd, J = 6.9, $2.5 \mathrm{~Hz}, 6$ $\mathrm{H}$, dipp[iso]-CH3, 7-H), 0.80 (d, $J=6.7 \mathrm{~Hz}, 3 \mathrm{H}$, dipp[iso]-CH3, 7-H) ppm. 13C $\{1 \mathrm{H}\}$ NMR (101 $\mathrm{MHz}, \mathrm{CDCl} 3): \delta=186.1$ (d, JRhC $=54.5 \mathrm{~Hz}, \mathrm{Rh}-\mathrm{CO}$ [trans to carbene], C-1a), 184.5 (d, JRhC = $74.9 \mathrm{~Hz}, \mathrm{Rh}-\mathrm{CO}$ [trans to chlorido], C-1b), 165.8 (d, JRhC = 44.8 Hz, Ccarbene, C-2), 149.7 (trzCq, C-3), 147.1 (dipp-Cq, C-4), 146.5 (dipp-Cq, C-4), 145.4 (dipp-Cq, C-4), 144.7 (dipp-Cq, C4), 136.4 (dipp-Cq, C-5), 132.2 (dipp-Cq, C-5), 132.0 (dipp-CH, C-6), 131.5 (dipp-CH, C-6), 125.3 (dipp-CH, C-7), 124.7 (dipp-CH, C-7), 124.6 (dipp-CH, C-7), $123.6(\operatorname{dipp}-\mathrm{CH}, \mathrm{C}-7), 73.1$ (Fc-CH, C-9), 71.8 (Fc-Cq, C-8), 70.1 (Fc- CH, C-10), 69.5 (Fc- CH, C-9), 67.2 (Fc-CH, C-9), 29.4 (dipp[iso]-CH, C-11), 29.3 (dipp[iso]-CH, C-11), 28.9 (dipp[iso]-CH, C-11), 28.7 (dipp[iso]-CH, C-11), 27.3 (dipp[iso]-CH3, C-12), 26.9 (dipp[iso]-CH3, C-12), 25.4 (dipp[iso]-CH3, C-12), 25.1 (dipp[iso]-CH3, C-12), 23.8 (dipp[iso]-CH3, C-12), 23.2 (dipp[iso]-CH3, C-12), 23.1 (dipp[iso]$\mathrm{CH} 3, \mathrm{C}-12$ ), 22.3 (dipp[iso]-CH3, C-12) ppm. C38H43CIFeN3O2Rh (with 1.6 equiv. H2O, 767.96): calcd. C 57.28, H 5.44, N 5.27; found C 57.15, H 5.52, N 4.88. ESI-HRMS (15 V, positive mode): calcd. for $[\mathrm{M}-\mathrm{CO}-\mathrm{Cl}]+704.1810$; found 704.1766. $\mathrm{IR}(\mathrm{CH} 2 \mathrm{Cl} 2)$ : $\tilde{\mathrm{vCO}}=$ 2075, $1992 \mathrm{~cm}-1$. 
[1-Ethyl-3-(2,6-diisopropylphenyl)-4-ferrocenyl-1,2,3-triazol-5-

ylidene]chloridodicarbonylrhodium(I) $\left[\mathrm{Rh}\left(\mathrm{B}^{\prime}\right) \mathrm{Cl}(\mathrm{CO}) 2\right](5)$ : Orange powder. Yield: $0.03 \mathrm{~g}$ (33 \%). 1H NMR (400 MHz, CDCl3): $\delta=7.55$ (t, J= $7.7 \mathrm{~Hz}, 1 \mathrm{H}$, dipp-CH, 1-H), $7.34(\mathrm{~m}, 2 \mathrm{H}$, dipp-CH, 2-H), $5.46(\mathrm{~m}, 1 \mathrm{H}, \mathrm{Fc}-\mathrm{H}, 3-\mathrm{H}), 5.30(\mathrm{~m}, 1 \mathrm{H}, \mathrm{Fc}-\mathrm{H}, 3-\mathrm{H}), 4.78(\mathrm{~m}, 2 \mathrm{H},-\mathrm{CH} 2 \mathrm{CH} 3,4-\mathrm{H})$, 4.50 (m, $2 \mathrm{H}, \mathrm{Fc}-\mathrm{H}, 5-\mathrm{H}), 4.27$ (m, $5 \mathrm{H}, \mathrm{Fc}-\mathrm{CH}, 6-\mathrm{H}), 2.85$ (m, $1 \mathrm{H}$, dipp[iso]-CH, 7-H), 2.28 (m, 1 $\mathrm{H}$, dipp[iso]-CH, 7-H), $1.72(\mathrm{t}, J=7.2 \mathrm{~Hz}, 3 \mathrm{H},-\mathrm{CH} 2 \mathrm{CH} 3,8-\mathrm{H}), 1.33(\mathrm{~d}, J=6.5 \mathrm{~Hz}, 6 \mathrm{H}$, dipp[iso]$\mathrm{CH} 3,9-\mathrm{H}), 1.21-1.06(\mathrm{~m}, 6 \mathrm{H}$, dipp[iso]-CH3, 9-H) ppm. 13C $\{1 \mathrm{H}\} \mathrm{NMR}(101 \mathrm{MHz}, \mathrm{CDCl}): \delta=$ $185.9(\mathrm{~d}, \mathrm{JRhC}=54.1 \mathrm{~Hz}, \mathrm{Rh}-\mathrm{CO}$ [trans to carbene], C-1a), 183.7 (d, JRhC $=75.2 \mathrm{~Hz}, \mathrm{Rh}-\mathrm{CO}$ [trans to chlorido], C-1b), 165.2 (d, JRhC $=40.0 \mathrm{~Hz}$, Ccarbene, C-2), 145.6 (dipp-Cq, C-3), 145.4 (trz-Cq, C-4), 136.4 (dipp-Cq, C-5), 131.3 (dipp-CH, C-6), 124.5 (dipp-CH, C-7), 123.5 (dipp-CH, C-7), 72.2 (Fc-CH, C-8), 71.3 (Fc-Cq, C-9), 71.1 (Fc-CH, C-10), 70.9 (Fc-CH, C-10), 70.2 (Fc-CH, C-11), 69.9 (Fc-CH, C-12), 46.4 (-CH2CH3, C-13), 29.0 (dipp[iso]-CH, C-14), 26.5 (dipp[iso]-CH3, C-15), 26.1 (dipp[iso]-CH3, C-15), 24.8 (dipp[iso]-CH3, C-15), 23.9 (dipp[iso]CH3, C-15), 22.8 (dipp[iso]-CH3, C-15), 21.9 (dipp[iso]-CH3, C-15), 14.9 (-CH2CH3, C-16) ppm. ESI-HRMS (15 V, positive mode): calcd. for [M - COCl]+ 572.0871; found 572.0882. IR $(\mathrm{CH} 2 \mathrm{Cl} 2): \tilde{v} \mathrm{CO}=2075,1992 \mathrm{~cm}-1$.

[1-Ethyl-3-(2,6-diisopropylphenyl)-4-phenyl-1,2,3-triazol-5ylidene]chloridodicarbonylrhodium(I) $\left[\mathrm{Rh}\left(\mathrm{C}^{\prime}\right) \mathrm{Cl}(\mathrm{CO}) 2\right](6)$ : Light yellow powder. Yield: $0.01 \mathrm{~g}$ (22\%). 1H NMR (400 MHz, CDCl3): $\delta=7.82(\mathrm{~m}, 1 \mathrm{H}$, dipp-CH, 1-H), $7.64(\mathrm{~m}, 1 \mathrm{H}, \mathrm{ph}-\mathrm{CH}, 2-\mathrm{H})$, $7.54(\mathrm{~m}, 4 \mathrm{H}, \mathrm{ph}-\mathrm{CH}, 3-\mathrm{H}), 7.50$ (d, J = $7.5 \mathrm{~Hz}, 2 \mathrm{H}$, dipp-CH, 4-H), 4.48 (dd, J=13.6, $6.6 \mathrm{~Hz}, 2$ $\mathrm{H},-\mathrm{CH} 2 \mathrm{CH} 3,5-\mathrm{H}), 2.56(\mathrm{~m}, 2 \mathrm{H}$, dipp[iso]-CH, 6-H), 1.54 (t, J = 6.9 Hz, $3 \mathrm{H},-\mathrm{CH} 2 \mathrm{CH} 3,7-\mathrm{H})$, $1.35(\mathrm{~d}, J=6.1 \mathrm{~Hz}, 6 \mathrm{H}$, dipp[iso]-CH3, 8-H), 1.10 (d, J = 6.30 Hz, $6 \mathrm{H}$, dipp[iso]-CH3, 8-H) ppm. $13 \mathrm{C}\{1 \mathrm{H}\} \mathrm{NMR}(101 \mathrm{MHz}, \mathrm{CDCl} 3): \delta=185.7$ (d, JRhC $=54.3 \mathrm{~Hz}$, Rh-CO [trans to carbene], C1a), 183.4 (d, JRhC = 75.0 Hz, Rh-CO [trans to chlorido], C-1b), 166.2 (d, JRhC = 40.5 Hz, Ccarbene, C-2), 146.3 (trz-Cq, C-3), 145.8 (dipp-Cq, C-4), 135.9 (dipp-Cq, C-5), 131.3 (dipp$\mathrm{CH}, \mathrm{C}-6$ ), 130.9, 130.3, 130.0, 128.9 (all ph- $\mathrm{CH}, \mathrm{C}-7$ ), 127.3 (ph-Cq, C-8), 124.0 (dipp-CH, C-9), 46.0 (-CH2CH3, C-10), 31.0 (dipp[iso]-CH, C-11), 29.1 (dipp[iso]-CH, C-11), 26.7 (dipp[iso]$\mathrm{CH} 3, \mathrm{C}-12$ ), 26.2 (dipp[iso]-CH3, C-12), 24.8 (dipp[iso]-CH3, C-12), 23.8 (dipp[iso]-CH3, C-12), 22.6 (dipp[iso]-CH3, C-12), $14.9(-\mathrm{CH} 2 \mathrm{CH} 3, \mathrm{C}-13)$ ppm. ESI-HRMS (15 V, positive mode): calcd. for $[\mathrm{M}-\mathrm{COCl}+\mathrm{ACN}]+505.1475$; found 505.1546. IR $(\mathrm{CH} 2 \mathrm{Cl} 2): \tilde{\mathrm{v} C O}=2074,1993 \mathrm{~cm}-$ 1.

Preparation of [1,3-Bis(2,6-diisopropylphenyl)-4-ferrocenium-1,2,3-triazol-5ylidene]chloridodicarbonylrhodium(I) Hexafluorophosphate [Rh( $\left.\left.A^{\prime} \mathrm{ox}\right) \mathrm{Cl}(\mathrm{CO}) 2\right] \mathrm{PF} 6$ (40x): AgPF6 $(0.04 \mathrm{~g}, 0.15 \mathrm{mmol})$ was added to a solution of $\mathbf{A}(0.10 \mathrm{~g}, 0.14 \mathrm{mmol})$ in deoxygenated $\mathrm{CH} 2 \mathrm{Cl} 2(5 \mathrm{~mL})$ at $-78^{\circ} \mathrm{C}$ and stirred for $10 \mathrm{~min}$. The solution was filtered and transferred to a solution of $[\mathrm{Rh}(\mathrm{cod}) \mathrm{Cl}] 2(0.03 \mathrm{~g}, 0.07 \mathrm{mmol})$ and $\mathrm{KN}[\mathrm{SiMe} 3] 2(0.03 \mathrm{~g}, 0.15 \mathrm{mmol})$ in THF (5 $\mathrm{mL}$ ) at $-78^{\circ} \mathrm{C}$ and stirred for $1 \mathrm{~h}$. Carbon monoxide then was bubbled through the solution for $5 \mathrm{~min}$. The FT-IR spectrum of the resulting green-brown solution was recorded to obtain the carbonyl stretching frequencies of 4ox. Alternatively, a solution of $1(0.10 \mathrm{~g}, 0.12 \mathrm{mmol})$ was treated with acetylferrocenium hexafluorophosphate $(0.05 \mathrm{~g}, 0.13 \mathrm{mmol}, 1.1$ equiv.) in $\mathrm{CH} 2 \mathrm{Cl} 2(10 \mathrm{~mL})$ at $-30{ }^{\circ} \mathrm{C}$, and the solution was warmed to room temperature. $\mathrm{CO}(\mathrm{g})$ was then bubbled through the solution for approximately $3 \mathrm{~min}$, and quantitative formation of 4ox was observed according to FT-IR spectroscopy.

4ox: Yield: $1.09 \mathrm{~g}(99 \%) . \mathrm{IR}(\mathrm{CH} 2 \mathrm{Cl} 2)$ : $\tilde{\mathrm{vCO}}=2082,2009 \mathrm{~cm}-1$. 


\section{Preparation of trans-(1,3-Diisopropylbenzimidazolin-2-ylidene)[1,3-bis(2,6-}

diisopropylphenyl)-4-ferrocenyl-1,2,3-triazol-5-ylidene]dibromidopalladium(II) [Pd(iPr2-

bimy)(Br)2(A')] (7): Compound $\mathbf{A}^{\prime}$ (0.03 g, $\left.0.05 \mathrm{mmol}\right)$ and [Pd(iPr2-bimy)(Br)2]2[16] (0.02 g, $0.03 \mathrm{mmol})$ were dissolved in C6D6 $(0.70 \mathrm{~mL})$ and stirred at room temperature for $30 \mathrm{~min}$. The NMR spectroscopic analysis of the reaction mixture indicated the clean formation of 7 . Single crystals of 7 were obtained by slow diffusion of hexane into the reaction mixture. Red crystals. Yield: $0.03 \mathrm{~g}(57 \%)$. $1 \mathrm{H} \mathrm{NMR}(400 \mathrm{MHz}, \mathrm{CDCl} 3): \delta=7.68-7.53(\mathrm{~m}, 4 \mathrm{H}$, dipp-CH, 1H), $7.44(\mathrm{~d}, J=7.9 \mathrm{~Hz}, 2 \mathrm{H}$, bimy-CH, 2-H), 7.34 (d, J = 7.8 Hz, $2 \mathrm{H}$, dipp-CH, 3-H), $7.12(\mathrm{~m}, 2 \mathrm{H}$, bimy- $\mathrm{CH}, 4-\mathrm{H}$ ), 6.56 (td, J = 14.1, $7.1 \mathrm{~Hz}, 1 \mathrm{H}$, bimy[iso]-CH, 5-H), 5.32 (sept, J = 7.1 Hz, $1 \mathrm{H}$, bimy[iso]-CH, 5-H), 55.08 (s, $2 \mathrm{H}, \mathrm{Fc}-\mathrm{CH}, 6-\mathrm{H}), 4.41$ (s, $5 \mathrm{H}, \mathrm{Fc}-\mathrm{CH}, 7-\mathrm{H}), 4.26$ (s, $2 \mathrm{H}, \mathrm{Fc}-\mathrm{CH}, 8-$ H), 3.09 (sept, $J=6.7 \mathrm{~Hz}, 1 \mathrm{H}$, dipp[iso]-CH, 9-H), 2.46 (sept, $J=6.8 \mathrm{~Hz}, 1 \mathrm{H}$, dipp[iso]-CH, 9$\mathrm{H}), 1.86(\mathrm{~d}, J=7.1 \mathrm{~Hz}, 6 \mathrm{H}$, dipp[iso]-CH3, 10-H), 1.46 (d, J=6.7 Hz, $6 \mathrm{H}$, dipp[iso]-CH3, 10-H), 1.40 (d, J = 7.0 Hz, $6 \mathrm{H}$, dipp[iso]-CH3, 10-H), 1.15 (d, J = 6.8 Hz, $6 \mathrm{H}$, dipp[iso]-CH3, 10-H), $1.09(\mathrm{~m}, 12 \mathrm{H}$, bimy[iso]-CH3, 11-H) ppm. 13C $\{1 \mathrm{H}\}$ NMR (101 MHz, CDCl3): $\delta=179.5(\mathrm{Cq}$, NCN[bimy]-Cq, C-1), 162.2 (Ccarbene, C-2), 147.4 (trz-Cq, C-3), 147.3 (dipp-Cq, C-4), 146.1 (dipp-Cq, C-4), 136.8 (dipp-Cq, C-5), 133.9 (dipp-Cq, C-5), 133.6 (bimy-Cq, C-6), 132.6 (dipp$\mathrm{CH}, \mathrm{C}-7), 131.6$ (dipp-CH, C-7), 130.6 (dipp-CH, C-7), 124.7 (dipp-CH, C-8), 123.4 (dipp-CH, C8), 121.6 (dipp- $\mathrm{CH}, \mathrm{C}-8$ ), 112.6 (bimy- $\mathrm{CH}, \mathrm{C}-9$ ), 112.6 (bimy-CH, C-9), 73.0 (Fc-Cq, C-10), 72.0 (Fc-CH, C-11), 71.1 (Fc-CH, C-11), 70.3 (Fc- $\mathrm{CH}, \mathrm{C}-12), 69.4$ (Fc- $\mathrm{CH}, \mathrm{C}-11), 68.9$ (Fc-CH, C-11), 54.0 (bimy[iso]-CH, C-13), 53.3 (bimy[iso]-CH, C-13), 29.7 (dipp[iso]-CH, C-14), 28.6 (dipp[iso]-CH, C-14), 27.6 (dipp[iso]-CH3, C-15), 25.2 (dipp[iso]-CH3, C-15), 23.6 (dipp[iso]$\mathrm{CH} 3, \mathrm{C}-15$ ), 22.7 (dipp[iso]-CH3, C-15), 21.1 (bimy[iso]- $\mathrm{CH} 3, \mathrm{C}-16$ ), 20.8 (bipy[iso]-CH3, C-16) ppm.

Crystal Structure Determination: Single crystal X-ray diffraction data for A, Aox, 1, 2 and 4 were collected with a Bruker Apex II-CCD detector using Mo-K $\alpha$ radiation $(\lambda=0.71073 \AA$ ), while for $\mathbf{A}^{\prime}$ and $\mathbf{7}$, single-crystal $\mathrm{X}$-ray diffraction data were collected with a Bruker AXS detector using Mo-K $\alpha$ radiation $(\lambda=0.71073 \AA$ ). Crystals were selected under oil, mounted on nylon loops then immediately placed in a cold stream of N2. Structures were solved and refined using Olex2 and SHELXTL[32] (A, Aox, 1, 2 and 4), or using Olex2 with the Superflip[33] structure solution program using charge flipping and refined with the ShelXL[32c] refinement package using least-squares minimisation. CCDC 1521461 (for A), 1521462 (for B), 1521465 (for C), 1521463 (for 1), 1521466 (for 2), 1521460 (for 4), 1521459 (for 7), 1521458 (for $\mathbf{A}^{\prime}$ ), and 1521464 (for Aox) contain the supplementary crystallographic data for this paper. These data can be obtained free of charge from The Cambridge Crystallographic Data Centre.

Crystal Data for Compound A: C37.5H47Cl3F6FeN3P ( $M=846.95 \mathrm{~g}$ mol-1), monoclinic, space group $C 2 / c, a=22.8718(17) \AA, b=14.9273(10) \AA, c=24.0533(19) \AA, \alpha=90^{\circ}, b=$

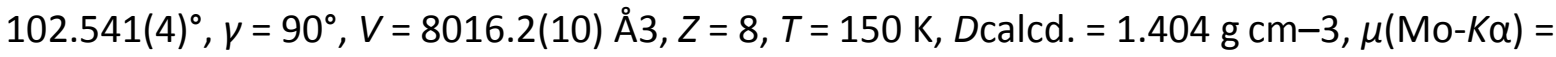
$0.675 \mathrm{~mm}-1,137039$ reflections measured $\left(4.456^{\circ} \leq 2 \vartheta \leq 54.324^{\circ}\right), 8877$ unique (Rint $=$ 0.0681 , Rsigma $=0.0240)$, which were used in all calculations. The final $R 1$ was $0.0638[I>$ $2 \sigma(I)]$, and $w R 2$ was 0.1240 (all data).

Crystal Data for Compound A': C36H43FeN3 ( $M=573.58 \mathrm{~g}$ mol-1), orthorhombic, space group Pbca, $a=17.3078(8) \AA, b=19.5725(9) \AA, c=37.0542(15) \AA, \alpha=90^{\circ}, b=90^{\circ}, \gamma=90^{\circ}, V$ $=12552.4(10) \AA ̊ \Omega 3, Z=16, T=100 \mathrm{~K}, D$ calcd. $=1.214 \mathrm{~g} \mathrm{~cm}-3, \mu(\mathrm{Cu}-\mathrm{K \alpha})=0.509 \mathrm{~mm}-1,45482$ 
reflections measured $\left(4.162^{\circ} \leq 2 \vartheta \leq 48.246^{\circ}\right), 9929$ unique ( $R$ int $=0.1027, R$ sigma $\left.=0.0893\right)$, which were used in all calculations. The final $R 1$ was $0.1116[I>2 \sigma(I)]$, and $w R 2$ was 0.1354 (all data).

Crystal Data for Compound Aox: C36.73H45.45Cl1.45FeF12N3P2 ( $M=926.10 \mathrm{~g}$ mol-1), triclinic, space group $P 1, a=12.3556(9) \AA, b=13.0788(10) \AA, c=16.2759(12) \AA, \alpha=$ $113.596(2)^{\circ}, B=90.660(2)^{\circ}, \gamma=115.747(2)^{\circ}, V=2115.5(3) \AA ̊ 3, Z=2, T=150 \mathrm{~K}, D$ calcd. $=$ $1.454 \mathrm{~g} \mathrm{~cm}-3, \mu(\mathrm{Mo}-K \alpha)=0.607 \mathrm{~mm}-1,82093$ reflections measured $\left(5.184^{\circ} \leq 2 \vartheta \leq 53.616^{\circ}\right)$, 9054 unique ( $\operatorname{Rint}=0.0409$, Rsigma $=0.0267)$, which were used in all calculations. The final $R 1$ was $0.0717[I>2 \sigma(I)]$, and $w R 2$ was 0.1562 (all data).

Crystal Data for Compound 1: C44H54CIFeN3Rh ( $M=819.11 \mathrm{~g}$ mol-1), monoclinic, space group $P 121 / n 1, a=12.1296(6) \AA, b=18.2052(10) \AA, c=17.6479(10) \AA, \alpha=90^{\circ}, b=$

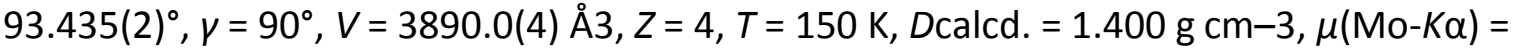
$0.900 \mathrm{~mm}-1,199624$ reflections measured $\left(2.24^{\circ} \leq 2 \vartheta \leq 30.60^{\circ}\right), 11951$ unique ( $R$ int $=$ $0.0991, R$ sigma $=0.0486$ ), which were used in all calculations. The final $R 1$ was 0.0767 [ $I>$ $2 \sigma(I)]$, and $w R 2$ was 0.0816 (all data).

Crystal Data for Compound 2: $\mathrm{C} 35 \mathrm{H} 44 \mathrm{Cl} 4 \mathrm{FeN} 3 \mathrm{Rh}(M=808.30 \mathrm{~g}$ mol-1), monoclinic, space group $C 2 / c, a=23.530(8) \AA, b=12.3540(16) \AA, c=15.6199(19) \AA, \alpha=100.010(4)^{\circ}, b=$ $105.064(4)^{\circ}, \gamma=115.626(4)^{\circ}, V=7069.0(4) \AA 3, Z=8, T=150 \mathrm{~K}, D$ calcd. $=1.519 \mathrm{~g} \mathrm{~cm}-3$, $\mu(\mathrm{Mo}-K \alpha)=1.209 \mathrm{~mm}-1,104552$ reflections measured $\left(4.642^{\circ} \leq 2 \vartheta \leq 53.092^{\circ}\right), 7307$ unique ( $R$ int $=0.0596$, $R$ sigma $=0.0254)$, which were used in all calculations. The final $R 1$ was $0.0479[I>2 \sigma(I)]$, and $w R 2$ was 0.1073 (all data).

Crystal Data for Compound 4: $\mathrm{C} 38 \mathrm{H} 43 \mathrm{ClFeN3O2Rh}(M=767.96 \mathrm{~g} \mathrm{~mol}-1)$, triclinic, space group $P 1, a=11.3010(15) \AA, b=15.700(5) \AA, c=20.188(7) \AA, \alpha=100.010(4)^{\circ}, b=$ 105.064(94) $)^{\circ}, \gamma=115.626(4)^{\circ}, V=1793.1(4) \AA 33, Z=2, T=150 \mathrm{~K}, D$ calcd. $=1.422 \mathrm{~g} \mathrm{~cm}-3$, $\mu($ Mo- $K \alpha)=0.975 \mathrm{~mm}-1,64511$ reflections measured $\left(4.794^{\circ} \leq 2 \vartheta \leq 56.25^{\circ}\right), 8529$ unique ( $R$ int $=0.0980, R$ sigma $=0.0560$ ), which were used in all calculations. The final $R 1$ was $0.0863[I>2 \sigma(I)]$, and $w R 2$ was 0.1688 (all data).

Crystal Data for Compound 7: C49H61Br2FeN5Pd ( $M=1042.09 \mathrm{~g}$ mol-1), monoclinic, space group $P 21 / c, a=10.3405(6) \AA, b=16.6247(9) \AA, c=27.1462(15) \AA, \alpha=90^{\circ}, b=$ 97.1132(11) $)^{\circ}, y=90^{\circ}, V=4630.7(4) \AA 33, Z=4, T=153 \mathrm{~K}$, Dcalcd. $=1.495 \mathrm{~g} \mathrm{~cm}-3, \mu($ Mo- $K \alpha)=$ $2.466 \mathrm{~mm}-1,62071$ reflections measured $\left(5.054^{\circ} \leq 2 \vartheta \leq 52.838^{\circ}\right), 9469$ unique ( $R$ int $=$ $0.0349, R$ sigma $=0.0205)$, which were used in all calculations. The final $R 1$ was $0.0283[I>$ $2 \sigma(I)]$, and $w R 2$ was 0.0656 (all data).

Electrochemistry: The $\mathrm{CVs}$ at a glassy carbon electrode in $\mathrm{CH} 2 \mathrm{Cl} 2$ were recorded using a three-electrode cell. The reference electrode was a non-aqueous $\mathrm{Ag} / \mathrm{Ag}+$ electrode, separated by the test solution by a frit with fine porosity. A glassy carbon disc $(3.0 \mathrm{~mm}$ diameter) was the working electrode, and the counter electrode was a platinum wire. Measurements were done with a Metrohm $\mu$ Autolab type III potentiostat, using NOVA 2.0 electrochemistry software at scan rates of $100 \mathrm{mV} \mathrm{s}-1$. The test compound $(1.0 \mathrm{~mm})$ and the internal standard [Fe( $n 5-\mathrm{C} 5 \mathrm{Me} 5) 2](1.0 \mathrm{~mm})$ were added to a deoxygenated solution of 
[ $n \mathrm{Bu} 4 \mathrm{~N}][\mathrm{PF} 6]$ (0.1 m; supporting electrolyte) in HPLC-grade $\mathrm{CH} 2 \mathrm{Cl} 2\left\{\mathrm{vs} . \mathrm{Ag} / \mathrm{Ag}+, E^{\circ \prime}=-0.54 \mathrm{~V}\right.$ for the couple $[\mathrm{Fe}(\mathrm{\eta}-\mathrm{C} 5 \mathrm{H} 5) 2] 0 /+1$, referenced to the ferrocene/ferrocenium couple at $0 \mathrm{~V}$.

Catalysis: All hydroformylation reactions were conducted in triplicate in a $90 \mathrm{~mL}$ stainlesssteel pipe reactor, to which the catalyst precursor (1-3) $(5.74 \times 10-3 \mathrm{mmol})$, substrate 1 octene $(0.805 \mathrm{~g}, 7.175 \mathrm{mmol})$ and internal standard $n$-decane $(0.204 \mathrm{~g}, 1.435 \mathrm{mmol})$ were added and dissolved in toluene $(5 \mathrm{~mL})$. The airtight reactor was purged with nitrogen (three times) then purged with syngas (CO/H2, 1:1) (twice), after which it was pressurized with syngas to the desired pressure and heated to the required temperature. When the reaction time was reached, the reactor was depressurized and cooled to room temperature. The samples were analysed by gas chromatography, and the products were confirmed against authentic iso-octene and aldehyde standards. Optimization of reaction conditions was done for catalyst precursor 1, by varying of the syngas pressure (30-50 bar), temperature (55-75 ${ }^{\circ} \mathrm{C}$ ) and reaction time (4-8 h). The reactivity of the oxidized compound 1ox was evaluated by the addition of an oxidant (acetylferrocenium hexafluorophosphate) as an additive to 1 .

\section{Acknowledgements}

F. D. and T. W. gratefully acknowledge financial support from the Fonds der Chemischen Industrie (FCI). G. S. S. gratefully acknowledges financial support from the University of Cape Town and the NRF-DST Centre of Excellence in Catalysis (C*Change). D. I. B. and D. A. gratefully acknowledge the National Research Foundation, South Africa (NRF 87890, 97202 and 104205), and Sasol Technology R\&D Pty. Ltd., South Africa for financial support.

\section{References}

[1] For selected examples of redox-switchable homogeneous catalysts, see:

a)T.-R. Chen, F.-S. Wu, H.-P. Lee and K. H.-C. Chen, J. Am. Chem. Soc., 2016, 138, 3643-3646;

b) A. B. Biernesser, K. R. Delle Chiaie, J. B. Curley and J. A. Byers, Angew. Chem. Int. Ed., 2016, 55, 5251-5254; Angew. Chem., 2016, 128, 5337;

c) D. N. Lastovickova, H. Shao, G. Lu, P. Liu, C. W. Bielawski, Chem. Eur. J. 2016, DOI: 10.1002/chem.201605738;

d) J. J. DeveryIII and C. R. J. Stephenson, Nature, 2015, 519, 42-43;

e) A. B. Biernesser, B. Li and J. A. Byers, J. Am. Chem. Soc., 2013, 135, 16553-16560;

f) S. Mortezaei, N. R. Catarinea and J. W. Canary, J. Am. Chem. Soc., 2012, 134, 8054-8057;

g) A. G. Tennyson, V. M. Lynch and C. W. Bielawski, J. Am. Chem. Soc., 2010, 132, 9420-9429;

h) M. R. Ringenberg, S. L. Kokatam, Z. M. Heiden and T. B. Rauchfuss, J. Am. Chem. Soc., 2008, 130, 788-789;

i) R. T. Hembre and J. S. McQueen, Angew. Chem. Int. Ed. Engl., 1997, 36, 65-67;

Angew. Chem., 1997, 109, 79;

j) I. M. Lorkovic, R. R. DuffJr and M. S. Wrighton, J. Am. Chem. Soc., 1995, 117, 3617-3618.

[2] For selected, recent examples of redox-switchable catalysts with a ferrocenyl-substituted ligand, see:

a) S. Ibánez, M. Poyatos, L. N. Dawe, D. Gusev and E. Peris, Organometallics, 2016, 35, 2747-2758;

b) S. M. Quan, X. Wang, R. Zhang and P. L. Diaconescu, Macromolecules, 2016, 49, 6768-6778;

c) S. M. Shepard and P. L. Diaconescu, Organometallics, 2016, 35, 2446-2453;

d) P. Neumann, H. Dib, A.-M. Caminade and E. Hey-Hawkins, Angew. Chem. Int. Ed., 2015, 54, 311314;Angew. Chem., 2015, 127, 316; 
e) L. Hettmanczyk, S. Manck, C. Hoyer, S. Hohloch and B. Sarkar, Chem. Commun., 2015, 51, 1094910952;

f) L. A. Brown, J. L. Rhinehart and B. K. Long, ACS Catal., 2015, 5, 6057-6060;

g) P. Neumann, H. Dib, A. Sournia-Saquet, T. Grell, m. Handke, A.-M. Camindade and E. Hey-Hawkins, Chem. Eur. J., 2015, 21, 6590-6604;

h) K. Arumugam, C. D. VarnadoJr, S. Sproules, V. M. Lynch and C. W. Bielawski, Chem. Eur. J., 2013, 19, 10866-10875;

i) E. M. Broderick, N. Guo, C. S. Vogel, C. Xu, J. Sutter, J. T. Miller, K. Meyer, P. Mehrkhodavandi and P. L. Diaconescu, J. Am. Chem. Soc., 2011, 133, 9278-9281;

j) E. M. Broderick, N. Guo, T. Wu, C. S. Vogel, C. Xu, J. Sutter, J. T. Miller, K. Meyer, T. Cantat and P. L. Diaconescu, Chem. Commun., 2011, 47, 9897-9899;

k) C. K. A. Gregson, V. C. Gibson, N. J. Long, E. L. Marshall, P. J. Oxford and A. J. P. White, J. Am.

Chem. Soc., 2006, 128, 7410-7411;

I) M. Süssner and H. Plenio, Angew. Chem. Int. Ed., 2005, 44, 6885-6888;

Angew. Chem., 2005, 117, 7045.

[3] a) S. Siangwata, S. Chulu, C. L. Oliver, G. S. Smith, Appl. Organomet. Chem., DOI:

10.1002/aoc.3593;

b) M. Madalska, P. Lönnecke and E. Hey-Hawkins, J. Mol. Catal. A, 2014, 383-394, 137-142;

c) M. W. P. Bebbington, S. Bontemps, G. Bouhadir, M. J. Hanton, R. P. Tooze, H. van Rensburg and D. Bourissou, New J. Chem., 2010, 34, 1556-1559;

d) A. M. Trzeciak, P. Štěpnička, E. Mieczyńska and J. J. Ziólkowski, J. Organomet. Chem., 2005, 690, 3260-3267;

e) J.-C. Hierso, F. Lacassin, R. Broussier, R. Amardeil and P. Meunier, J. Organomet. Chem., 2004, 689, 766-769;

f) X. Peng, Z. Wang, C. Xia and K. Ding, Tetrahedron Lett., 2008, 49, 4862-4864;

g) M. Laly, R. Broussier and B. Gautheron, Tetrahedron Lett., 2000, 41, 1183-1185;

h) S. Stockmann, P. Lönnecke, S. Bauer and E. Hey-Hawkins, J. Organomet. Chem., 2014, 751, 670677;

i) J. D. Unruh and J. R. Christenson, J. Mol. Catal., 1982, 14, 19-34.

[4] G. K. Ramollo, M. J. López-Gómez, D. C. Liles, L. C. Matsinha, G. S. Smith and D. I. Bezuidenhout, Organometallics, 2015, 34, 5745-5753.

[5] For design strategies of Rh, I-NHC complexes as hydroformylation catalysts, see reviews and references cited therein:

a) W. Gil, A. M. Trzeciak, Coord. Chem. Rev. 2011, 255, 473-483;

b) A. R. Almeida, A. F. Peixoto, M. J. F. Calvete, P. M. P. Gois and M. M. Pereira, Curr. Org. Synth., 2011, 8, 764-775;

c) S. Díez-González, N. Marion and S. P. Nolan, Chem. Rev., 2009, 109, 3612-3676;

d) J. M. Praetorius and C. M. Crudden, Dalton Trans., 2008, 4079-4094;

e) A. S. Veige, Polyhedron, 2008, 27, 3177-3189;

f) E. Peris and R. H. Crabtree, Coord. Chem. Rev., 2004, 248, 2239-2246.

[6] a) P. Mathew, A. Neels and M. Albrecht, J. Am. Chem. Soc., 2008, 130, 13534-13535;

b) G. Guisado-Barrios, J. Bouffard, B. Donnadieu and G. Bertrand, Angew. Chem. Int. Ed., 2010, 49, 4759-4762;Angew. Chem., 2010, 122, 4869.

[7] The synthesis, spectroscopic characterization and single-crystal X-ray structures of the new triazolium salts $\mathbf{A}-\mathbf{C}$ are reported in the Supporting Information. 
[8] J. Bouffard, B. K. Keitz, R. Tonner, G. Guisado-Barrios, G. Frenking, R. H. Grubbs and G. Bertrand, Organometallics, 2011, 30, 2617-2627.

[9] K. Barral, A. D. Moorhouse and J. E. Moses, Org. Lett., 2007, 9, 1809-1811.

[10] a) G. Guisado-Barrios, J. Bouffard, B. Donnadieu and G. Bertrand, Organometallics, 2011, 30, 6017-6021;

b) T. Romero, R. A. Orenes, A. Tárraga and P. Molina, Organometallics, 2013, 32, 5740-5753.

[11] a) S. Burling, L. D. Field, H. L. Li, B. A. Messerle and P. Turner, Eur. J. Inorg. Chem., 2003, 31793184;

b) J. M. Praetorius, D. P. Allen, R. Wang, J. D. Web, F. Grein, P. Kennepohl and C. M. Crudden, J. Am. Chem. Soc., 2008, 130, 3724-3725;

c) J. Cipot-Wechsler, D. Covelli, J. M. Praetorius, N. Hearns, O. V. Zenkina, E. C. Keske, R. Wang, P. Kennepohl and C. M. Crudden, Organometallics, 2012, 31, 7306-7315;

d) E. C. Keske, O. V. Zenkina, A. Asadi, H. Sun, J. M. Praetorius, D. P. Allen, D. Covelli, B. O. Patrick, R. Wang, P. Kennepohl, B. R. James and C. M. Crudden, Dalton Trans., 2013, 42, 7414-7423;

e) M. Moser, B. Wucher, D. Kunz and F. Rominger, Organometallics, 2007, 26, 1024-1030.

[12] See, for example: R. C. J. Atkinson, N. J. Long in Ferrocenes. Ligands, Materials and Biomolecules (Ed.: P. Štěpnička), John Wiley \& Sons, Ltd., Chichester, 2008, pp. 3-32.

[13] a) I. Strydom, G. Guisado-Barrios, I. Fernández, D. C. Liles, E. Peris, D. I. Bezuidenhout, Chem. Eur. J., DOI: 10.1002/chem.201604567;

b) G. Kleinhans, G. Guisado-Barrios, D. C. Liles, G. Bertrand and D. I. Bezuidenhout, Chem. Commun., 2016, 52, 3504-3507;

c) D. Mendoza-Espinosa, R. González-Olvera, G. E. Negrón-Silva, D. Angeles-Beltrán, O. R. SuárezCastillo, A. Álvarez-Hernández and R. Santillan, Organometallics, 2015, 34, 4529-4542;

d) T. V. Q. Nguyen, W.-J. Yoo and S. Kobayashi, Angew. Chem. Int. Ed., 2015, 54, 9209-9212;

Angew. Chem., 2015, 127, 9341-9344

e) X. Yan, J. Bouffard, G. Guisado-Barrios, B. Donnadieu and G. Bertrand, Chem. Eur. J., 2012, 18, 14627-14631;

f) M. T. Zamora, M. J. Ferguson and M. Cowie, Organometallics, 2012, 31, 5384-5395;

g) A. Poulain, D. Canseco-Gonzalez, R. Hynes-Roche, H. Müller-Bunz, O. Schuster, H. Stoeckli-Evans,

A. Neels and M. Albrecht, Organometallics, 2011, 30, 1021-1029.

[14] a) C. A. Tolman, Chem. Rev., 1977, 77, 313-348;

b) S. Wolf and H. Plenio, J. Organomet. Chem., 2009, 694, 1487-1492.

[15] Calculated using the linear regression model: TEP $=0.8001$, vav(CO)Rh $+420 \mathrm{~cm}-1$ of: T. Dröge, F. Glorius, Angew. Chem. Int. Ed. 2010, 49, 6940-6952;Angew. Chem., 2010, 122, 7094.

[16] a) H. V. Huynh, Y. Han, R. Jothibasu and J. A. Yang, Organometallics, 2009, 28, 5395-5404;

b) D. Yuan and H. V. Huynh, Organometallics, 2012, 31, 405-412.

[17] D. I. Bezuidenhout, I. Fernández, B. van der Westhuizen, P. J. Swarts and J. C. Swarts, Organometallics, 2013, 32, 7334-7344.

[18] N. G. Connelly and W. E. Geiger, Chem. Rev., 1996, 96, 877-910. 
[19] a) D. I. Bezuidenhout, B. van der Westhuizen, P. J. Swarts, T. Chatturgoon, O. Q. Munro, I. Fernández and J. C. Swarts, Chem. Eur. J., 2014, 20, 4974-4985;

b) B. van der Westhuizen, J. M. Speck, M. Korb, D. I. Bezuidenhout and H. Lang, J. Organomet. Chem., 2014, 772-773, 18-26;

c) see ref.[17];

d) B. van der Westhuizen, J. M. Speck, M. Korb, J. Friedrich, D. I. Bezuidenhout and H. Lang, Inorg. Chem., 2013, 52, 14253-14264.

[20] a) See ref.[17];b) A. Hildebrandt, T. Rüffer, E. Erasmus, J. C. Swarts and H. Lang, Organometallics, 2010, 29, 4900-4905.

[21] See ref.[5a].

[22] R. Franke, D. Selent and A. Börner, Chem. Rev., 2012, 112, 5675-5732.

[23] a) For selected examples of Rh, I-NHC hydroformylation catalysts, see: M. S. Jeletic, M. T. Jan, I. Ghiviriga, K. A. Abboud, A. S. Veige, Dalton Trans. 2009, 2764-2776;

b) R. Lai, J.-C. Daran, A. Heumann, A. Zaragori-Benedetti and E. Rafi, Inorg. Chim. Acta, 2009, 362, 4849-4852;

c) W. Gil, A. M. Trzeciak and J. J. Ziólkowski, Organometallics, 2008, 27, 4131-4138;

d) see ref.[5d];

e) J. M. Praetorius, M. W. Kotyk, J. D. Webb, R. Y. Wang and C. M. Crudden, Organometallics, 2007, 26, 1057-1061;

f) S. Dastgir, K. S. Coleman, A. R. Cowley and M. L. H. Green, Organometallics, 2006, 25, 300-306;

g) M. Bortenschlager, M. Mayr, O. Nuyken and M. R. Buchmeiser, J. Mol. Catal. A, 2005, 233, 67-71;

h) A. Neveling, G. R. Julius, S. Cronje, C. Esterhuysen and H. G. Raubenheimer, Dalton Trans., 2005, 181-192;

i) M. Poyatos, P. Uriz, J. A. Mata, C. Claver, E. Fernández and E. Peris, Organometallics, 2003, 22, 440-444;

j) A. C. Chen, L. Ren, A. Decken and C. M. Crudden, Organometallics, 2000, 19, 3459-3461.

[24] M. Bortenschlager, J. Schutz, D. von Preysing, O. Nuyken, W. A. Herrmann and R. Weberskirch, J. Organomet. Chem., 2005, 690, 6233-6237.

[25] a) D. R. Anton and R. H. Crabtree, Organometallics, 1983, 2, 855-859;

b) J. A. Widegren and R. G. Finke, J. Mol. Catal. A, 2003, 198, 317-341.

[26] G. Doisneau, G. Balavoine and T. Fillebeen-Khan, J. Organomet. Chem., 1992, 425, 113-117.

[27] a) N. Nimitsiriwat, V. C. Gibson, E. L. Marshall, P. Takolpuckdee, A. K. Tomov, A. J. P. White, D. J. Williams, M. R. J. Elsegood and S. H. Dale, Inorg. Chem., 2007, 46, 9988-9997;

b) A. G. M. Barrett, M. R. Crimmin, M. S. Hill, P. B. Hitchcock, G. Kociok-Köhn and P. A. Procopiou, Inorg. Chem., 2008, 47, 7366-7376.

[28] C. Mintz and M. J. Walling, Org. Synth., 1969, 49, 9.

[29] G. Giordano and R. H. Crabtree, in: Inorganic Syntheses, Vol. 28: Reagents for Transition Metal Complex and Organometallic Syntheses (Ed.: R. J. Angelici), J. Wiley \& Sons, Hoboken, 1991, pp. 8889 ,

[30] H. Meerwein, Org. Synth., 1966, 46, 113. 
[31] M. R. Cerón, F. Li and L. Echegoyen, Chem. Eur. J., 2013, 19, 7410-7415.

[32] a) O. V. Dolomanov, L. J. Bourhis, R. J. Gildea, J. A. K. Howard and H. Puschmann, J. Appl. Crystallogr., 2009, 42, 339-341;

b) M. C. Burla, R. Caliandro, M. Camalli, B. Carrozzini, G. L. Cascarano, L. De Caro, C. Giacovazzo, G. Polidori, D. Siliqi and R. Spagna, J. Appl. Crystallogr., 2007, 40, 609-613;

c) G. M. Sheldrick, Acta Crystallogr., Sect. A, 2008, 64, 112-122.

[33] a) L. Palatinus and G. Chapuis, J. Appl. Crystallogr., 2007, 40, 786-790;

b) L. Palatinus and A. van der Lee, J. Appl. Crystallogr., 2008, 41, 975-984;

c) L. Palatinus, S. J. Prathapa and S. van Smaalen, J. Appl. Crystallogr., 2012, 45, 575-580. 